\title{
floodX: urban flash flood experiments monitored with conventional and alternative sensors
}

Matthew Moy de Vitry et al.

Correspondence to: Matthew Moy de Vitry (matthew.moydevitry@eawag.ch)

The copyright of individual parts of the supplement might differ from the CC BY 3.0 License. 


\section{Table of contents}

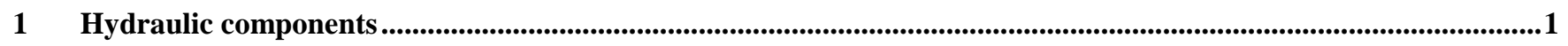

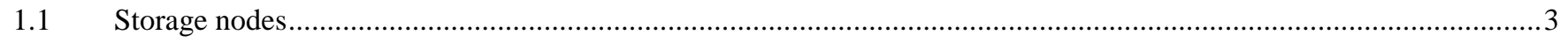

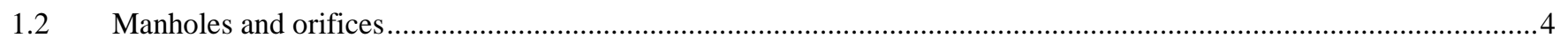

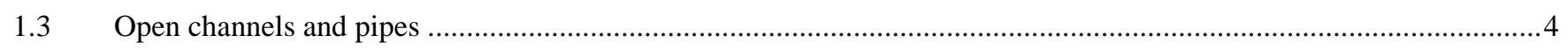

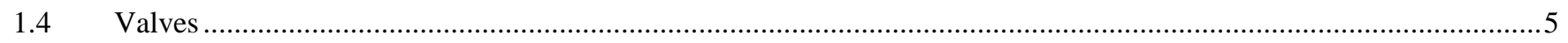

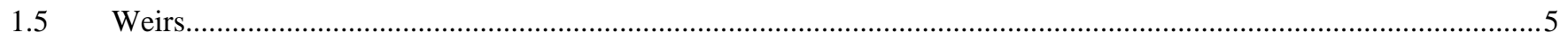

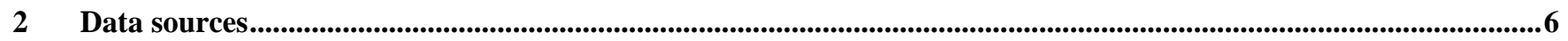

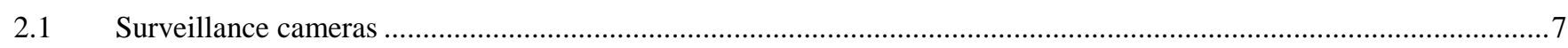

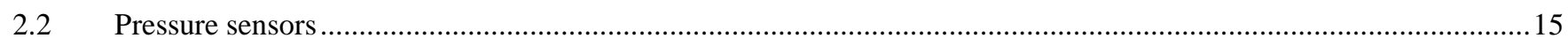

2.3 Temperature probes at opening $\mathrm{r} 3$ of manhole $\mathrm{m} 2$ (r3_t_onset_1/2/3/4) ................................................................19

2.4 Magnetic inductive flow sensor in pipe p1 (p1_q_mid_endress) ..........................................................................20

2.5 Water level and flow velocity in open channel c3 (c3_v_radar_nivus, c3_h_us_nivus, c3_v_radar_hach and

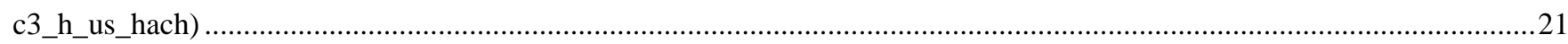

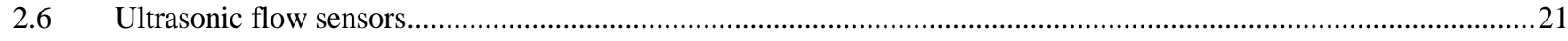

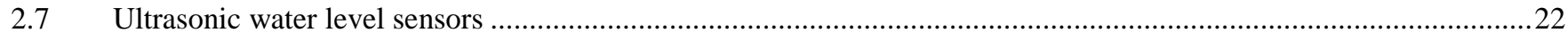

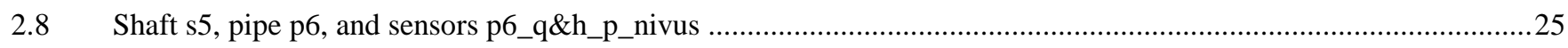

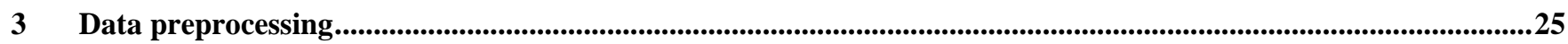

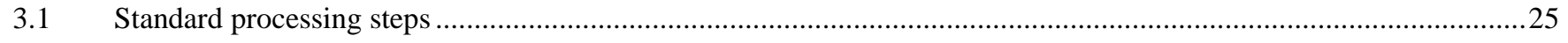

3.2 Reading sensor display images with optical character recognition …..............................................................26

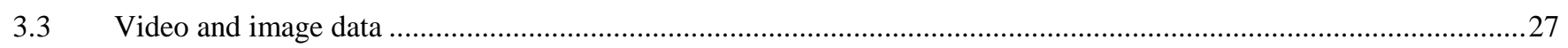

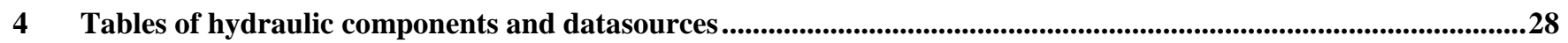

\section{Hydraulic components}

The principal hydraulic components are represented in Figure S1 and Figure S2, and are provided with detail in the plan "Plan of experimental setup and hydraulic components.pdf". 


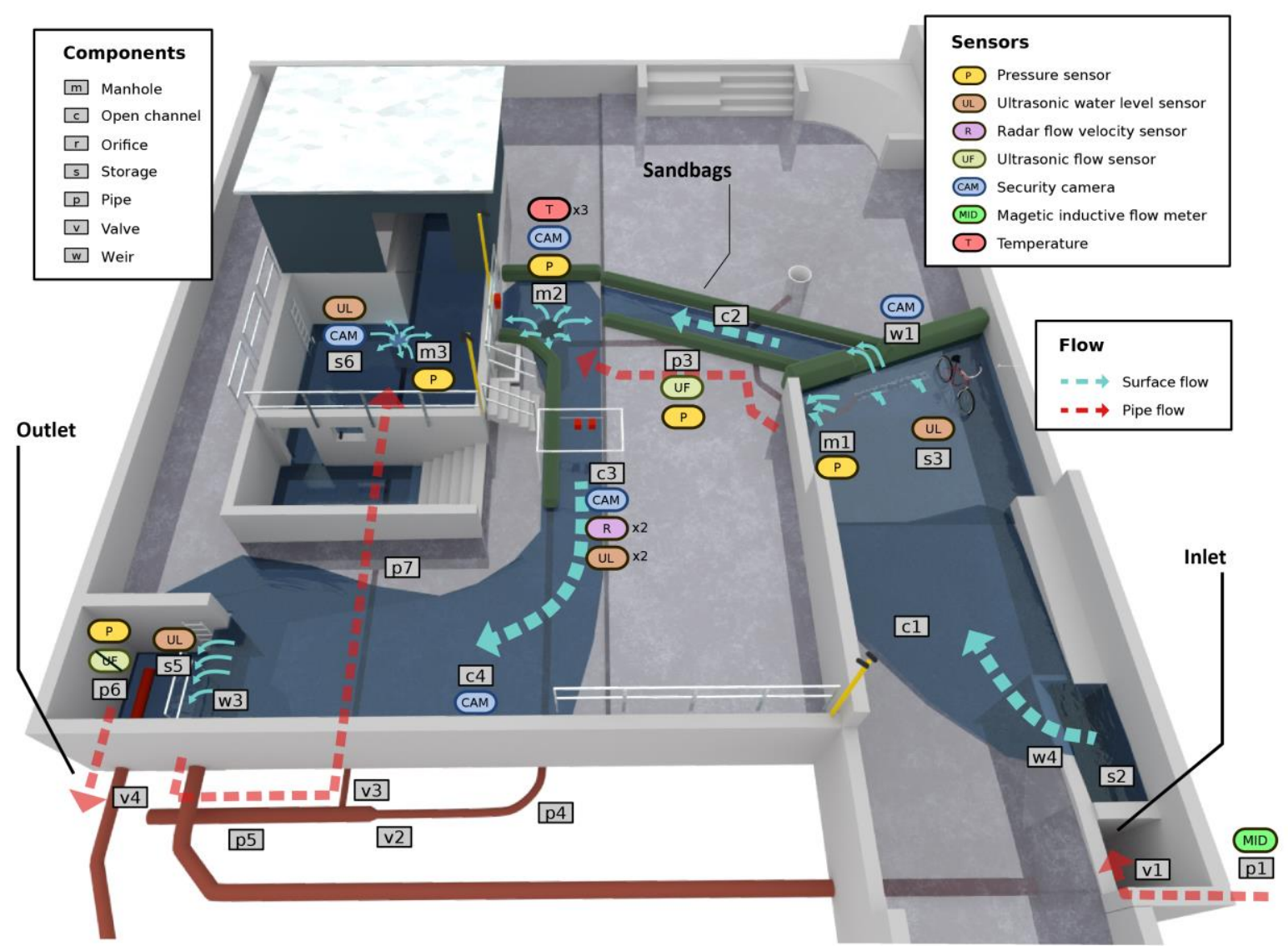

Figure S1: 3D rendering of flood facility, with approximate locations of sensors.
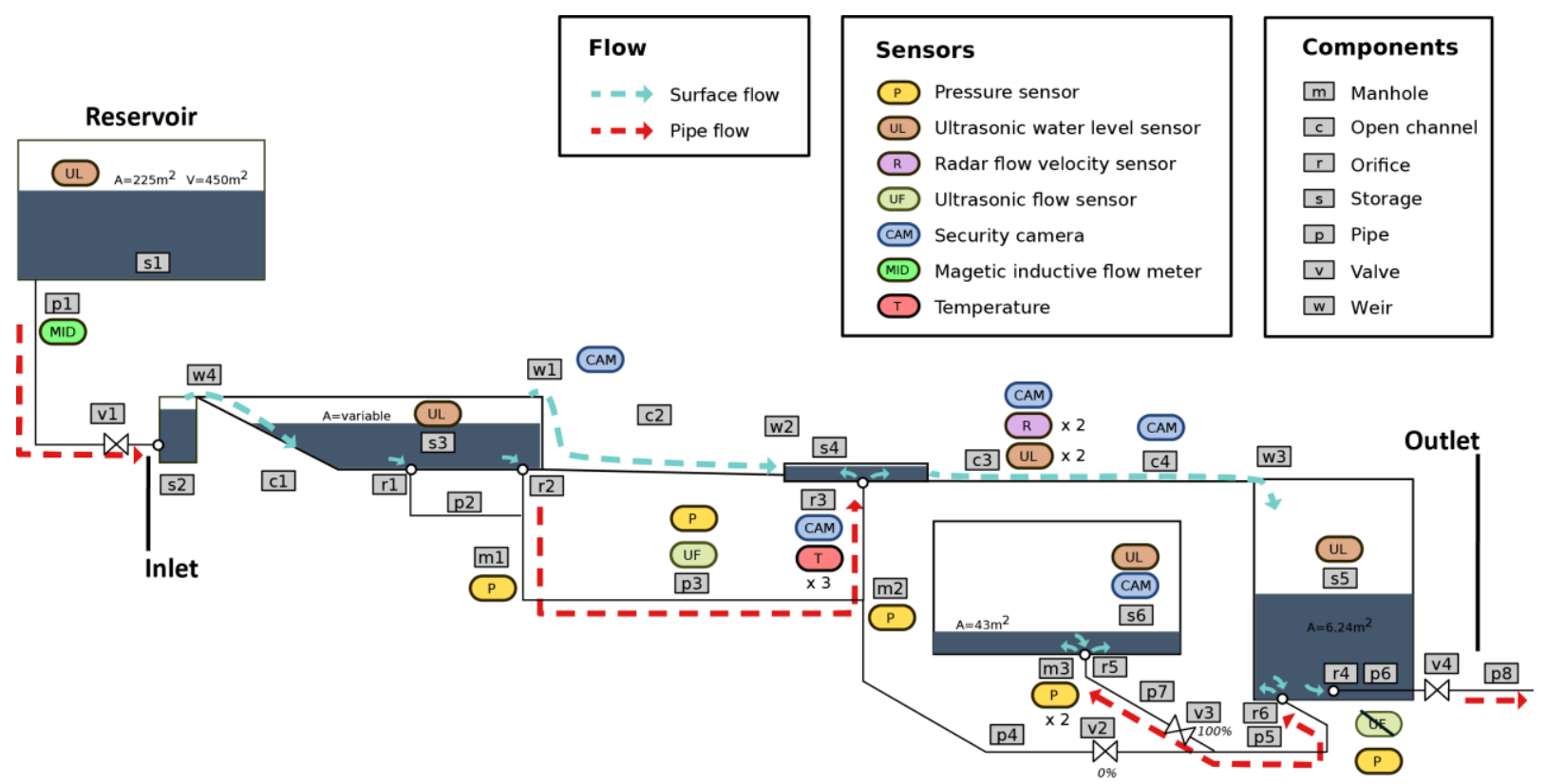

Figure S2: Diagram of hydraulic network, including components and sensors. 


\subsection{Storage nodes}

Storage nodes are ponds and shafts in which water can accumulate and in which the flow direction is not strictly defined. In the following tables and figures, information about storage nodes is provided. For storages s 3 and s5, more information is

Table S1: Key figures for storage nodes.

\begin{tabular}{lllll}
\hline Name & Inflows & Invert elevation $[\mathrm{m}]$ & Max Depth $[\mathrm{m}]$ & Storage function \\
\hline S1 & Yes & 427.28 & 2.15 & Vol $\left[\mathrm{m}^{3}\right]=225\left[\mathrm{~m}^{2}\right] *$ water level $[\mathrm{m}]$ \\
S2 & No & 417.75 & 3.0 & Vol $\left[\mathrm{m}^{3}\right]=2.94\left[\mathrm{~m}^{2}\right] *$ water level $[\mathrm{m}]$ \\
S3 & No & 419.94 & 0.7 & See Table S2 \\
S4 & No & 419.76 & 0.2 & Vol $\left[\mathrm{m}^{3}\right]=7.81\left[\mathrm{~m}^{2}\right] *$ water level $[\mathrm{m}]$ \\
S5 & No & 417.94 & 1.2 & See Figure S4 \\
S6 & No & 418.44 & 0.2 & Vol $\left[\mathrm{m}^{3}\right]=43\left[\mathrm{~m}^{2}\right] *$ water level $[\mathrm{m}]$ \\
\hline
\end{tabular}

Table S2: Level-volume table for storage s3.

\begin{tabular}{ll}
\hline Water level [m] & Volume [m3] \\
\hline $\mathbf{0}$ & 0 \\
$\mathbf{0 . 2 5}$ & 2.13 \\
$\mathbf{0 . 7}$ & 6.17 \\
\hline
\end{tabular}

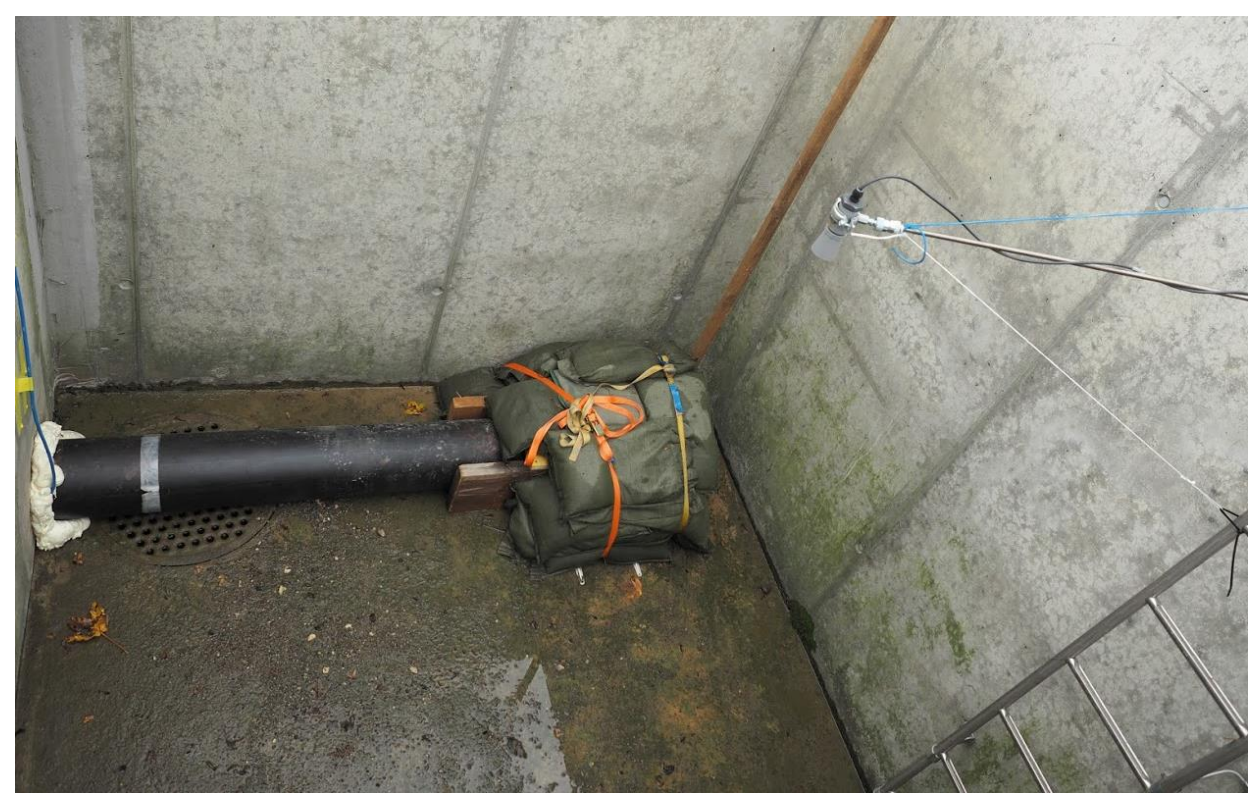

Figure S3: Pipe p6 in shaft s5 in which the flow meter p6_q\&h_p_nivus is located. Ultrasonic water level s5_h_us_maxbotix_1 can be seen on the right. 


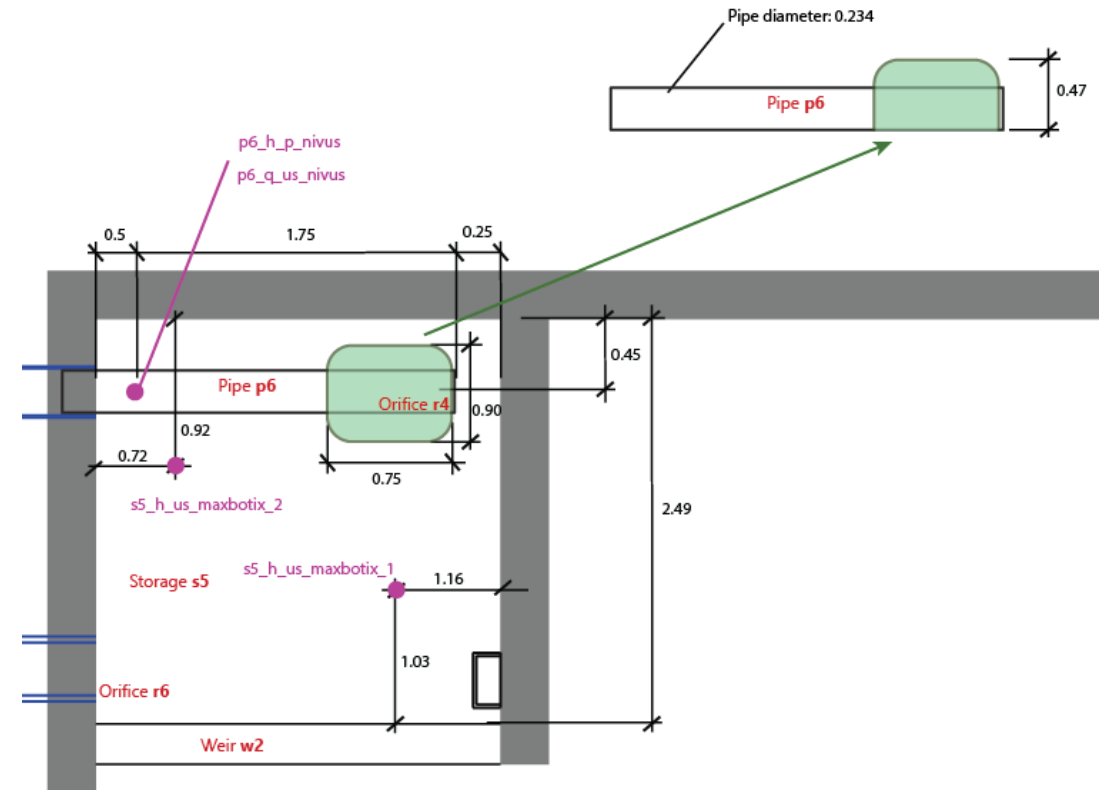

Figure S4: Shaft s5 with approximate locations of sensors and dimensions of sandbag pile. Units are meters unless indicated otherwise.

\subsection{Manholes and orifices}

Three manholes were active in the experimental setup, whereby manhole $\mathrm{m} 1$ is more of a gully pot (Table S3). Besides the orifices of the manholes, an additional orifice $\mathrm{r} 1$ is installed in storage $\mathrm{s} 3$ (Table S4).

Table S3: Characteristics of manholes.

\begin{tabular}{lllll}
\hline Name & Invert elevation $[\mathbf{m}]$ & Cover elevation $[\mathbf{m}]$ & Cover & Diameter $[\mathbf{m}]$ \\
\hline M1 & 418.34 & 419.94 & Grate & 0.6 \\
M2 & 417.41 & 419.76 & None & 0.8 \\
M3 & 417.44 & 418.44 & None & 0.6 \\
\hline
\end{tabular}

Table S4: Characteristics of orifices.

\begin{tabular}{|c|c|c|c|c|c|c|c|}
\hline Name & Elevation [m] & Cover & Type & Shape & Height [m] & Width [m] & Comments \\
\hline$R 1$ & 419.94 & Grate & Bottom & Rectangular & 0.2 & 2 & Long grate \\
\hline$R 2$ & 419.94 & Grate & Bottom & Rectangular & 0.6 & 0.6 & Orifice of manhole $\mathrm{m} 1$ \\
\hline$R 3$ & 419.76 & None & Bottom & Circular & 0.6 & 0.6 & Orifice of manhole $\mathrm{m} 2$ \\
\hline$R 4$ & 418.44 & None & Bottom & Circular & 0.6 & 0.6 & Orifice of manhole $\mathrm{m} 3$ \\
\hline
\end{tabular}

\subsection{Open channels and pipes}

Table S5 and Table S6 provide information about the open channels and pipes.

Table S5: Characteristics of open channels

\begin{tabular}{lllllllll}
\hline Name & Max depth [m] & Length [m] & Surface & Flow & Shape & Width [m] & Start elevation & End elevation \\
\hline C1 & 0.7 & 7.2 & Pavement & 1D & rectangular & 5.5 & 420.48 & 419.94 \\
C2 & 0.2 & 7.3 & Pavement & 1D & rectangular & 1 & 419.94 & 419.91 \\
C3 & No & 4.63 & Pavement & 1D & rectangular & 1.06 & 419.76 & 419.69 \\
C4 & No & 11 & Pavement & 2D & Ill-defined & variable & 419.69 & 419.47 \\
\hline
\end{tabular}


Table S6: Characteristics of pipes

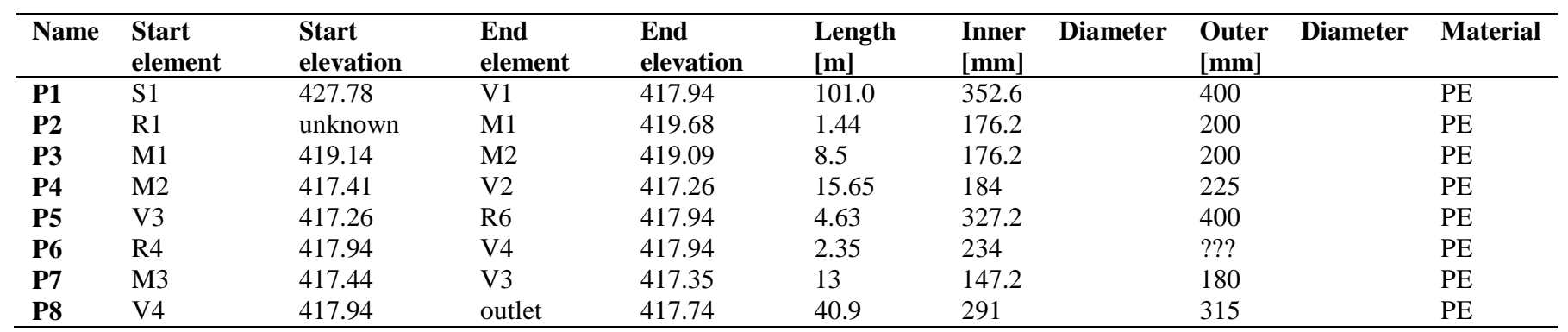

\subsection{Valves}

Two valves were operated during execution of the flood experiments: valve v1 controlled how much water entered the system via pipe $\mathrm{p} 1$, and valve $\mathrm{v} 4$ controls the rate at which water can leave the system.

Valves v1 and v4 are DESPONIA butterfly valves, for which the flow factors at different degrees of opening are provided in Table S7 and photos in Figure S5. In the experiment metadata, it is referred to the opening of the valves not in degrees but in notches $\left(0^{\circ}=\right.$ notch $0,90^{\circ}=$ notch 12$)$.

Table S7: Flow factor $K_{v}\left[\mathrm{~m}^{3} h^{-1}\right]$ for different degrees of opening.

\begin{tabular}{lllllllll}
\hline Degree of opening & $\mathbf{2 0}^{\circ}$ & $\mathbf{3 0}^{\circ}$ & $\mathbf{4 0}^{\circ}$ & $\mathbf{5 0}^{\circ}$ & $\mathbf{6 0}^{\circ}$ & $\mathbf{7 0}^{\circ}$ & $\mathbf{8 0}^{\circ}$ & $\mathbf{9 0}^{\circ}$ \\
\hline Valve v4 (DESPONIA plus PN 10 DN 300) & 200 & 505 & 890 & 1450 & 2100 & 3800 & 5960 & 6800 \\
Valve v1 (DESPONIA plus PN 10 DN 400) & 365 & 860 & 1500 & 2490 & 3980 & 6600 & 10200 & 11700 \\
\hline
\end{tabular}
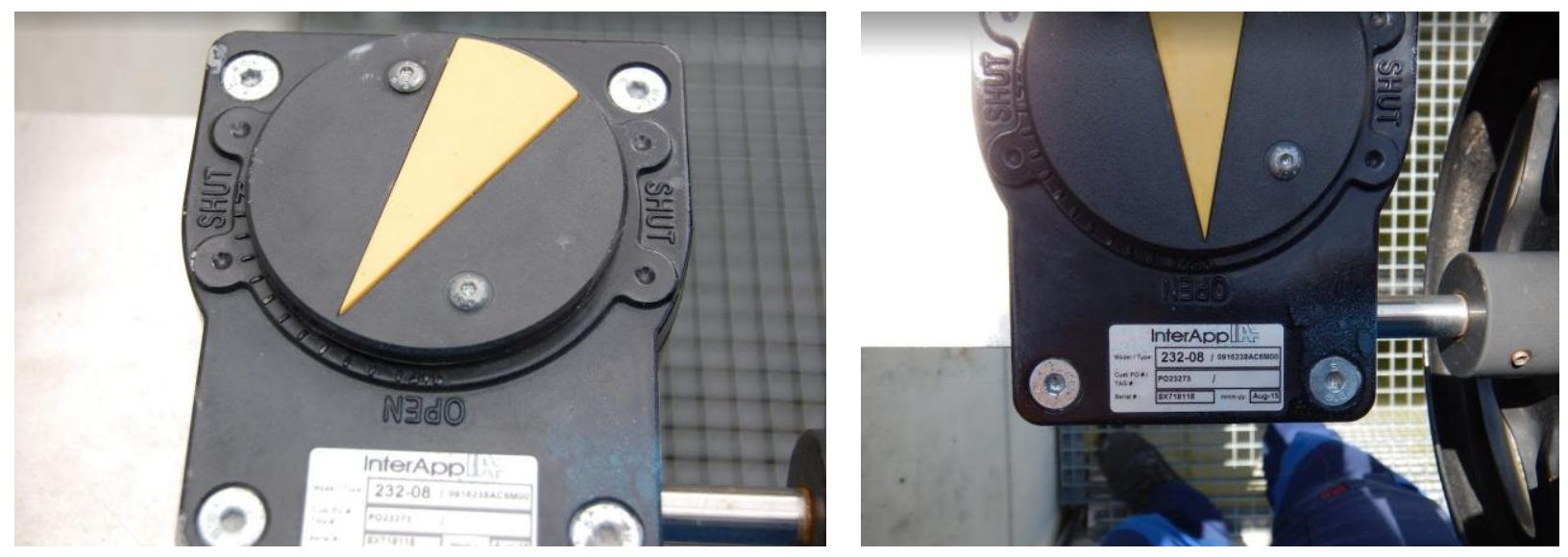

Figure S5: Gauges for valves v1 (left, set to the $8^{\text {th }}$ notch) and $v 4$ (right, fully open on the $12^{\text {th }}$ notch).

\subsection{Weirs}

There are four weirs in the experiment (see Figure S6 and Table S8). 


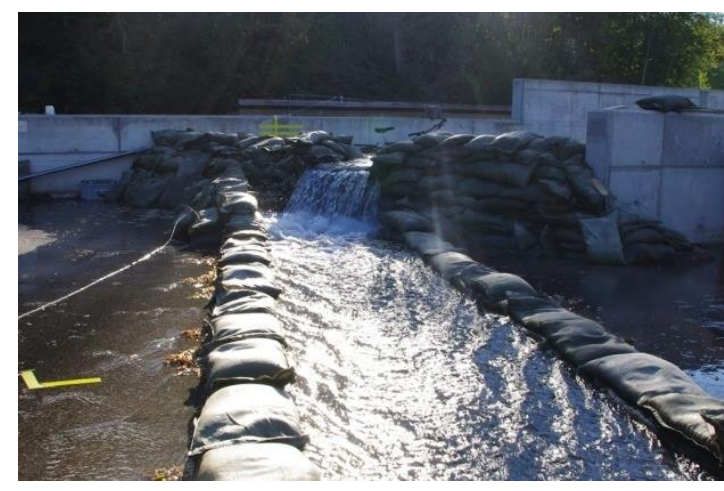

(a) Weir w1

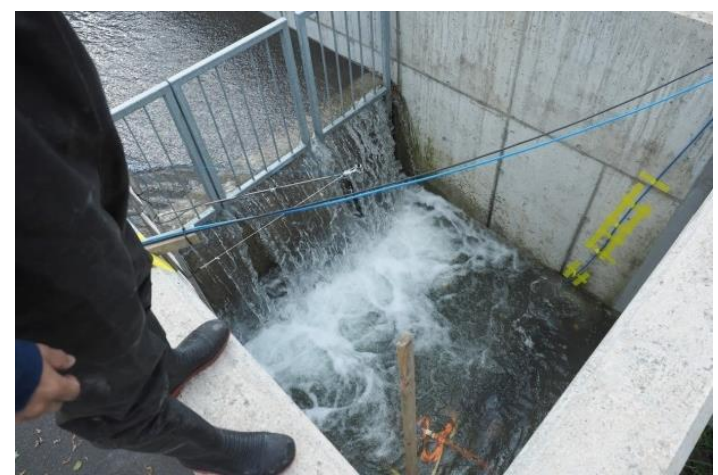

(c) Weir w3

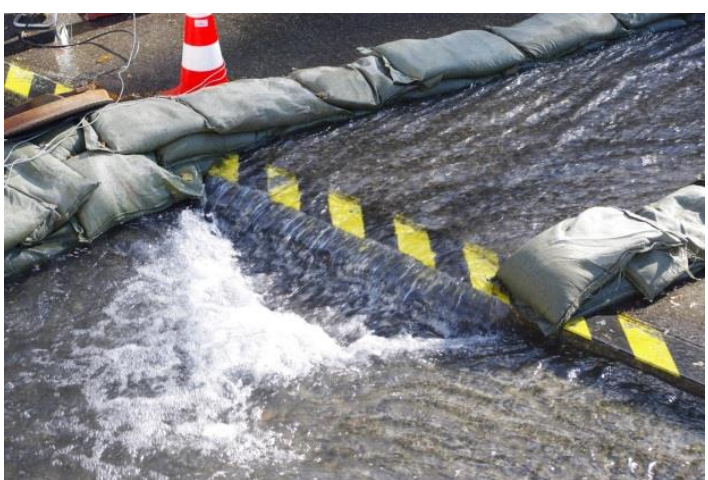

(b) Weir w2

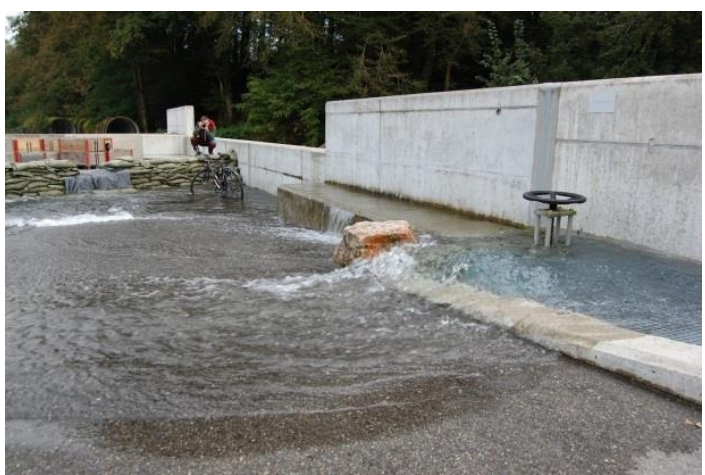

(d) Weir w4

Figure S6: Weirs in hydraulic network.

Table S8: Key figures for weirs in network.

\begin{tabular}{llll}
\hline & Length [m] & Elevation min [m] & Elevation max [m] \\
\hline w1 & 0.78 & 420.45 & 420.50 \\
w2 & 1.16 & 419.88 & 419.88 \\
w3 & 2.5 & 419.47 & 419.47 \\
w4 & 3.64 (poorly defined edge) & 420.48 & 420.79 \\
\hline
\end{tabular}

\section{Data sources}

For purpose of clarity, we define the term "datasource" as a sensor mounted at a given location with data being saved by a given logger. A total of 36 datasources are involved in the floodX experiments (Table S15). The naming system for datasources is as follows:

\section{[p1]_[q]_[mid]_[endress]_[logi]}

- $\quad$ p1: location of measurement (see Figure S2 for complete list of hydraulic components, each of which is a possible location)

- $\quad$ q: physical variable measured by sensor. Can be one of: q (flow), h (water level), v (surface velocity), t (temperature)

- mid: measuring principle of the sensor, one of: mid (magnetic-inductive), p (barometric), us (ultrasound) radar (Doppler radar) 
- $\quad$ endress: make of the sensor, one of: endress (for Endress+Hauser), maxbotix, nivus, hach, onset, instar

- logi: optional appendix for logging method or number to distinguish multiple sensors at same location; see floodX documentation for details

This formula applies to all sensors, with exception of the video cameras and temperature sensors for which the measurement principle is lacking.

\subsection{Surveillance cameras}

All surveillance cameras used were INSTAR IN-5907HD, which were fastened to masts and tethered if needed. For calibrating the cameras, marks were made on the ground and their positions were taken in a local reference system. An image with the marks visible, as well as the relative positions of the marks and camera, are provided for the cameras for which flow is visible.

\subsubsection{Video camera for storage area $\mathrm{s} 3$ and weir w1 (s3_cam1_instar)}

Camera s3_cam1_instar is an INSTAR IN-5907HD positioned to record the water level in the storage area s3. However, the camera can also see weir w1 and open channel c2 (see Figure S7 below).

ع: $0.15 @(9.776,4.99,4.035),(0.88,0.99,1.53), 0.0099,-0.135,0,(x),(\omega), f, k 1 \cdot 1 e 6, k 2 \cdot 1 e 9$

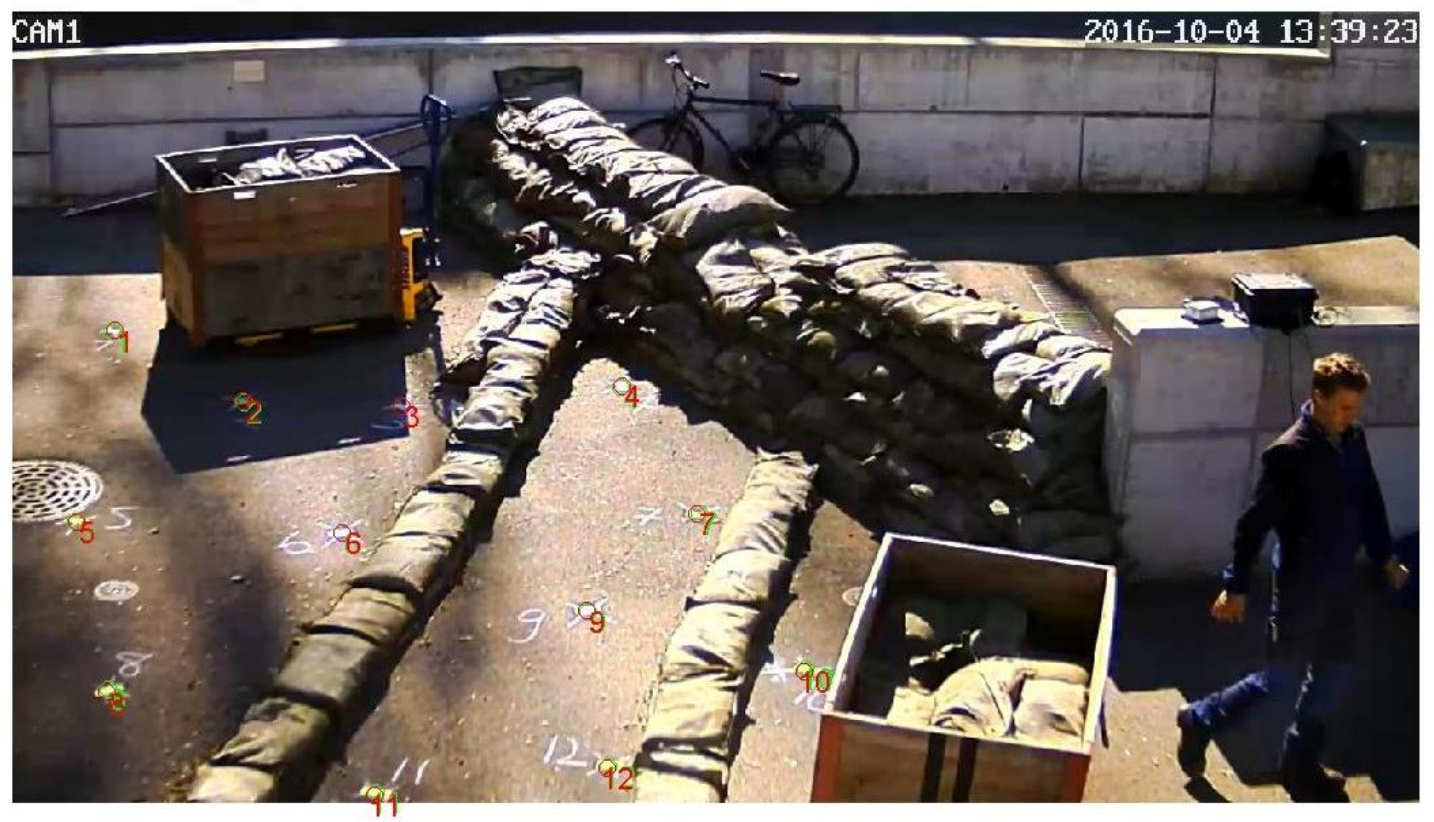

Figure S7: View from camera s3_cam1_instar, in which storage s3, weir w1, and channel c2 can be seen.

Table S9: Relative coordinates of camera CAM1 and calibration points.

\begin{tabular}{llll}
\hline & $\mathbf{X}$ & $\mathbf{Y}$ & $\mathbf{Z}$ \\
\hline CAM1 & 9.776 & 4.990 & 4.035 \\
point 1 & 0.016 & 0.001 & 0.030 \\
point 2 & 0.778 & 1.126 & 0.019 \\
point 3 & 0.629 & 1.955 & 0.010 \\
\hline
\end{tabular}




\begin{tabular}{llll}
\hline point 4 & 0.067 & 2.984 & 0.000 \\
point 5 & 2.322 & 0.886 & 0.017 \\
point 6 & 2.101 & 2.140 & 0.015 \\
point 7 & 1.500 & 3.631 & 0.002 \\
point 8 & 3.720 & 1.693 & 0.034 \\
point 9 & 2.510 & 3.352 & -0.002 \\
point 10 & 2.789 & 4.292 & -0.012 \\
point 11 & 4.072 & 2.924 & 0.014 \\
point 12 & 3.665 & 3.685 & -0.003 \\
\hline
\end{tabular}

Two methods are suggested for visually determining the water level in the storage area: First, regularly spaced markings were placed on the far wall (Figure S9) and second, a bicycle of known dimensions was placed in the storage area (Figure S8).

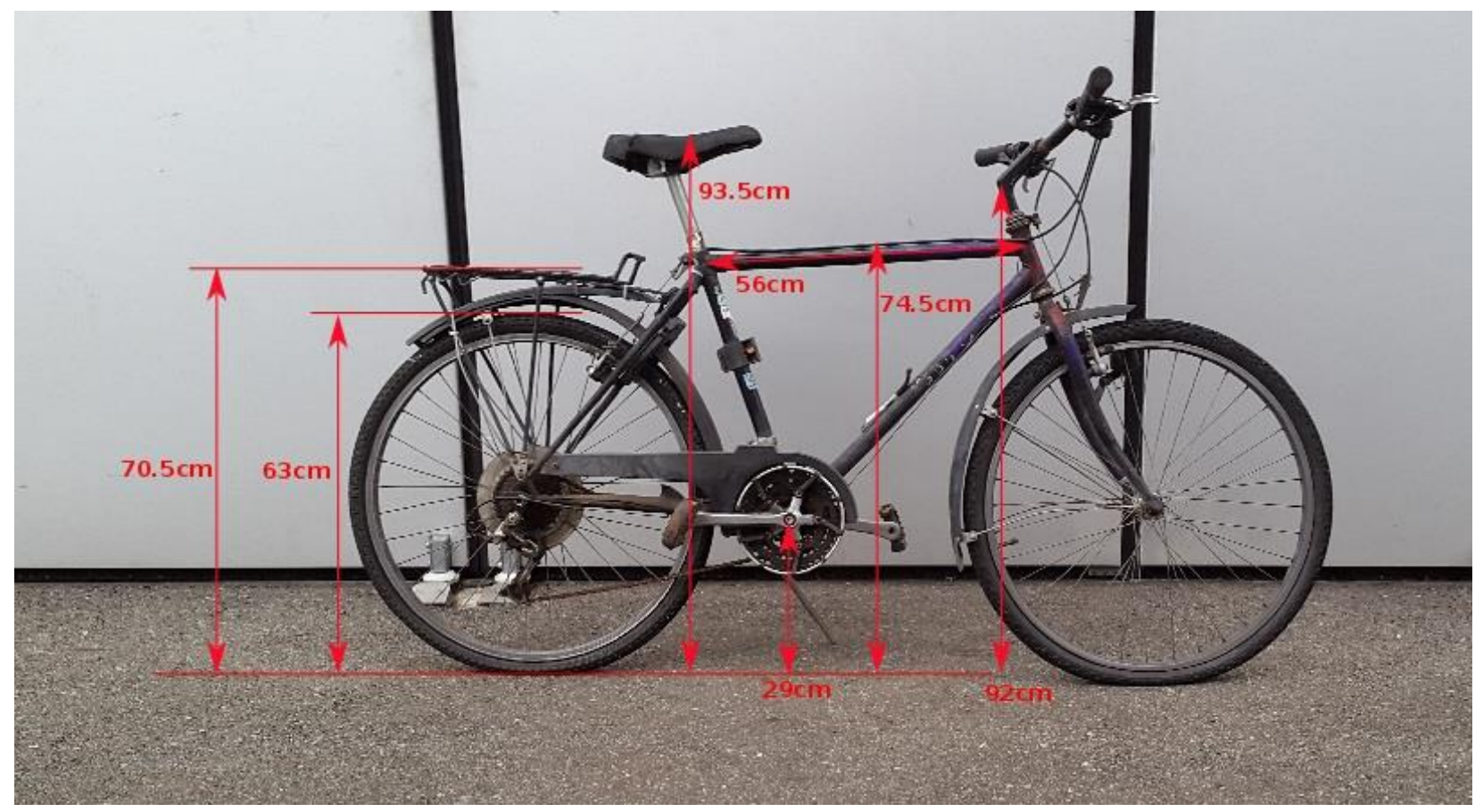

Figure S8: Dimensions of bicycle that was placed in storage area s3. 


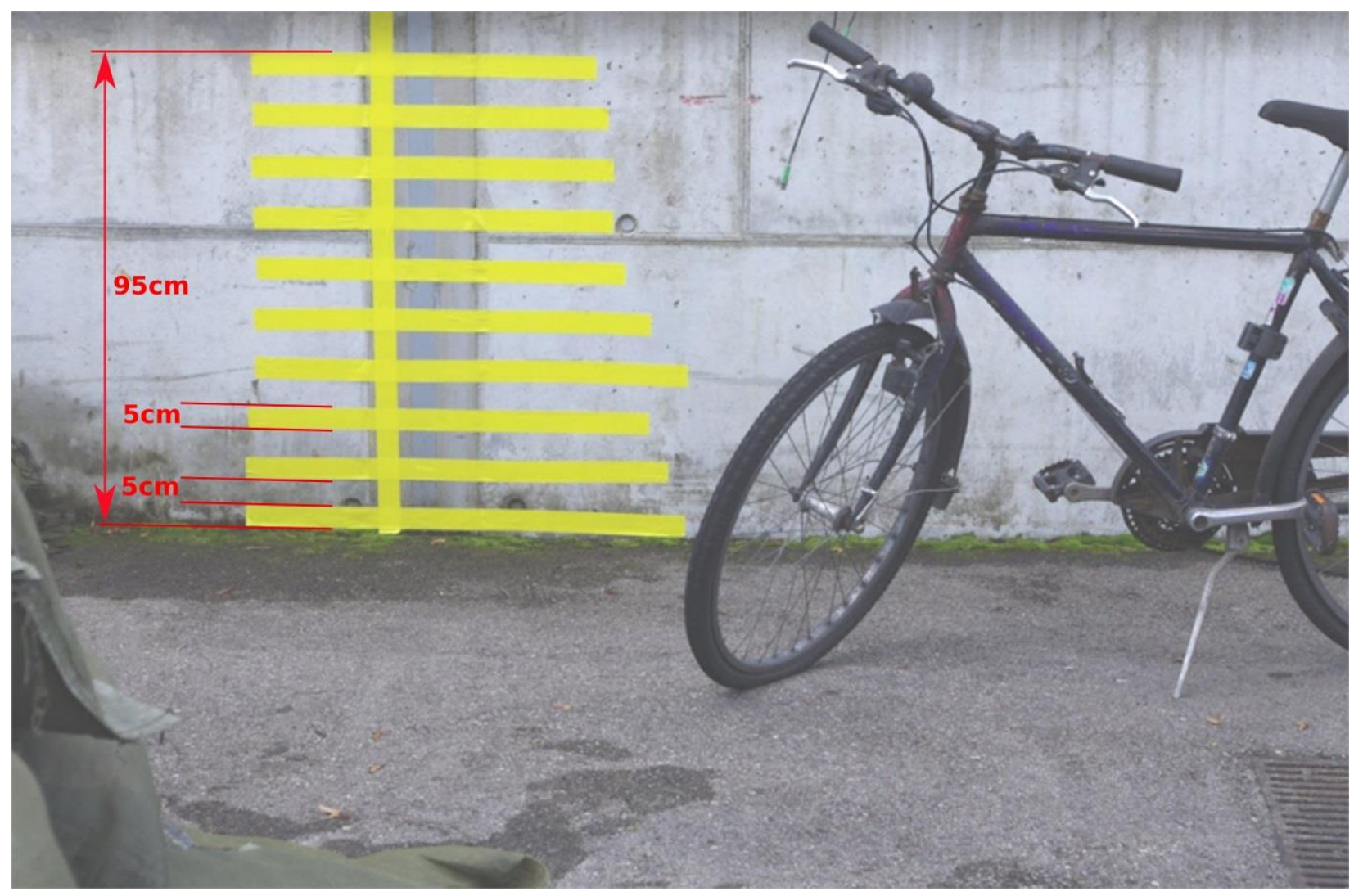

Figure S9: Wall markings in storage area s3. 


\subsubsection{Video camera for manhole opening r3 (r3_cam2_instar)}

Camera r3_cam2_instar is an INSTAR IN-5907HD positioned to detect water overflowing out of manhole m2 (Figure S10).

ع: $0.19 @(11.409,7.318,4.913),(0.64,1.25,1.93), 0.0099,-0.135,0,(x),(\omega), f, k 1 \cdot 1 \mathrm{e} 6, \mathrm{k} 2 \cdot 1 \mathrm{e} 9$

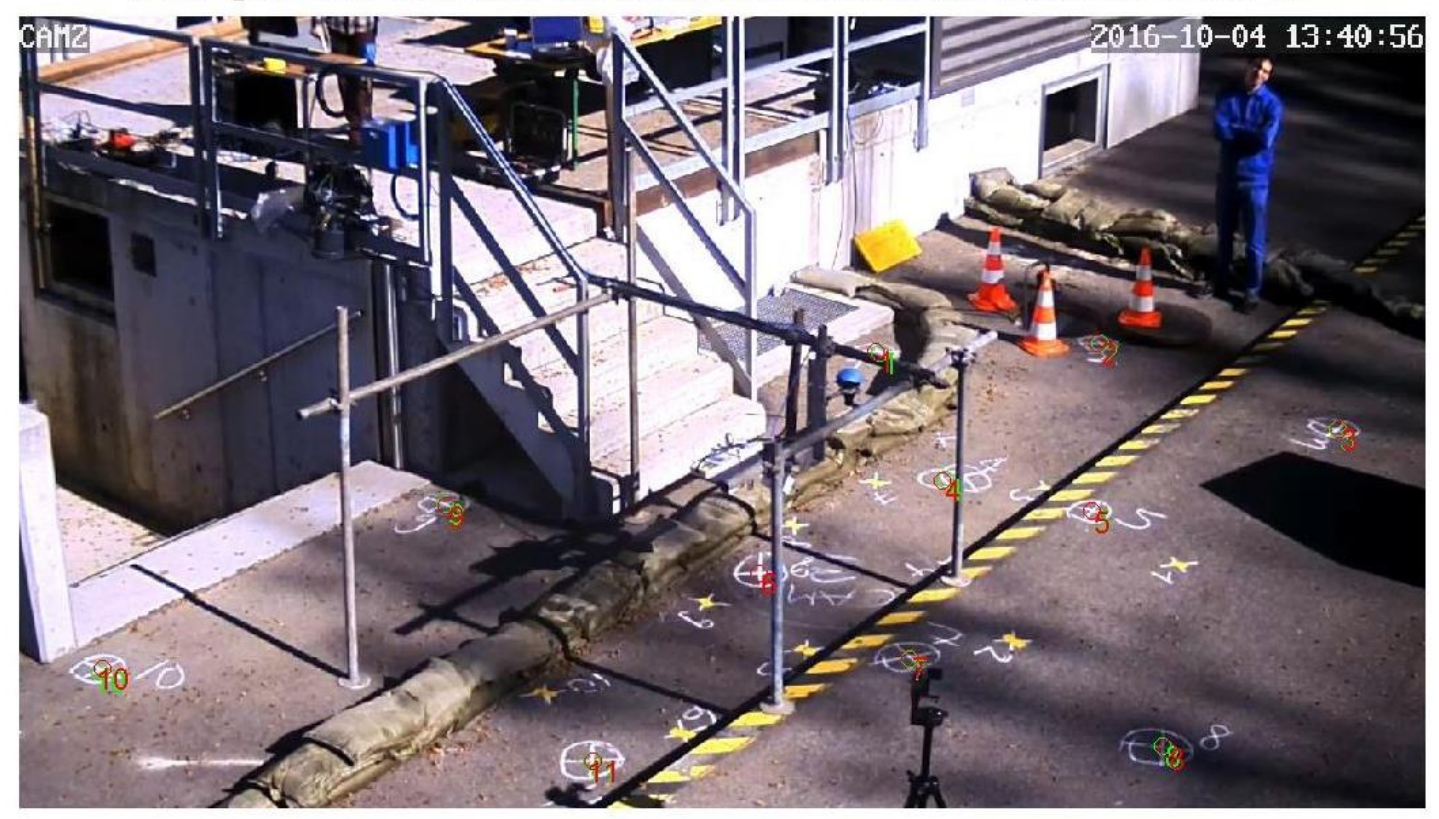

Figure S10: Calibration points and camera parameters of CAM2.

Table S10: Relative coordinates of camera CAM2 and calibration points.

\begin{tabular}{llll}
\hline & $\mathbf{X}$ & $\mathbf{Y}$ & $\mathbf{Z}$ \\
\hline CAM2 & 11.409 & 7.318 & 4.913 \\
point 1 & 1.092 & 0.804 & 0.024 \\
point 2 & 0.000 & 1.848 & 0.014 \\
point 3 & 0.596 & 3.831 & 0.156 \\
point 4 & 2.435 & 2.131 & 0.009 \\
point 5 & 2.498 & 3.105 & 0.138 \\
point 6 & 3.950 & 1.966 & 0.004 \\
point 7 & 4.381 & 3.146 & 0.134 \\
point 8 & 4.409 & 4.500 & 0.155 \\
point 9 & 4.243 & 0.043 & -0.100 \\
point 10 & 6.672 & 0.000 & -0.084 \\
point 11 & 5.759 & 2.401 & -0.028 \\
\hline
\end{tabular}

\subsubsection{Video camera for channel c3 (c3_cam3_instar)}

Camera c3_cam3_instar is an INSTAR IN-5907HD positioned to view water flowing in channel c3. 
є: $0.19 @(0.685,-1.508,3.596),(0.67,-0.16,-0.55), 0.0098,-0.127,0,(\mathrm{x}),(\omega), \mathrm{f}, \mathrm{k} 1 \cdot 1 \mathrm{e} 6, \mathrm{k} 2 \cdot 1 \mathrm{e} 9$

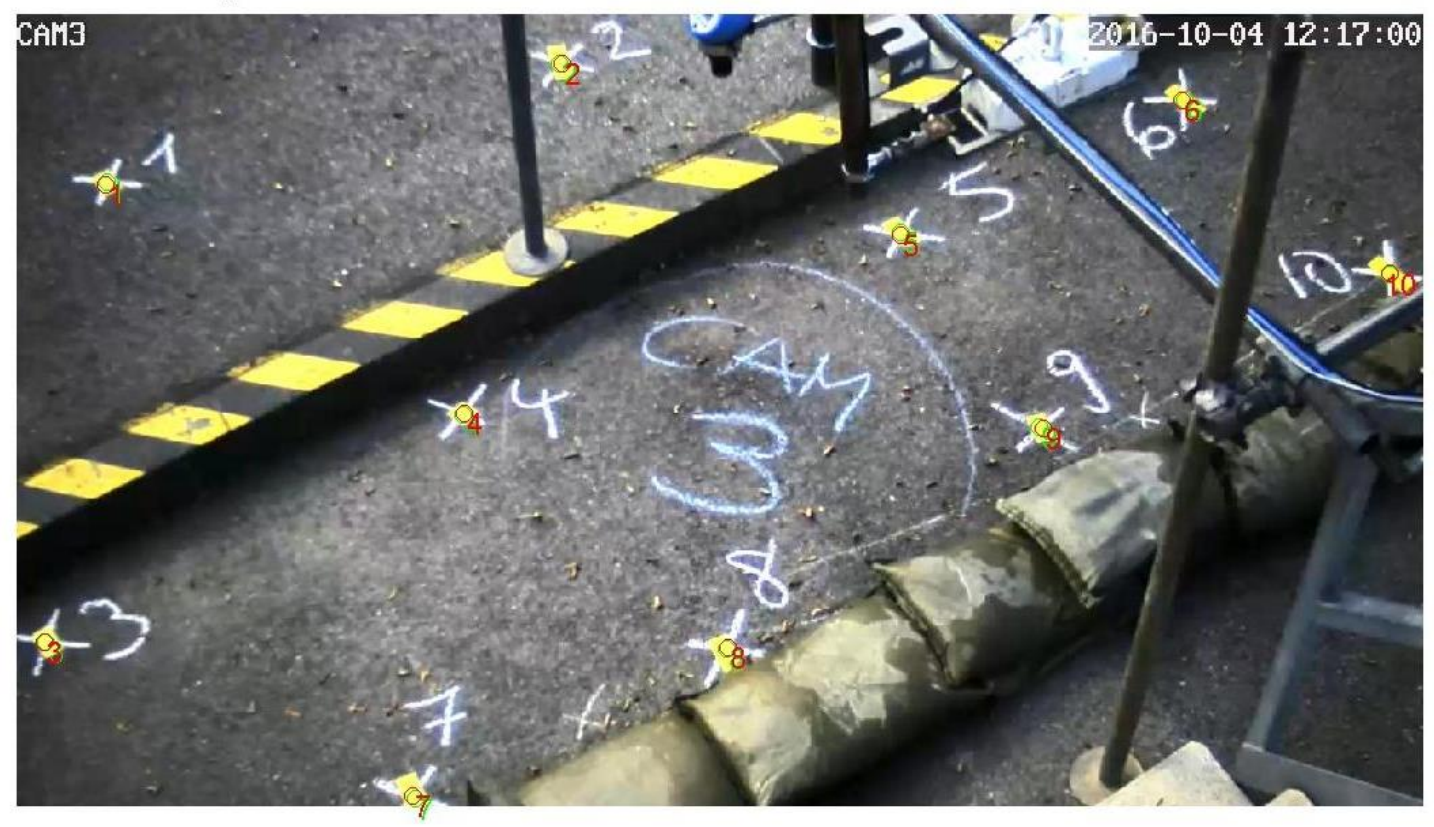

Figure S11: Calibration points and camera parameters of CAM3.

Table S11: Relative coordinates of camera CAM3 and calibration points.

\begin{tabular}{llll}
\hline & $\mathbf{X}$ & $\mathbf{Y}$ & $\mathbf{Z}$ \\
\hline CAM3 & 0.685 & -1.508 & 3.596 \\
point 1 & 1.141 & 2.435 & 0.147 \\
point 2 & 2.335 & 2.131 & 0.147 \\
point 3 & 0.513 & 1.301 & 0.000 \\
point 4 & 1.630 & 1.347 & 0.003 \\
point 5 & 2.787 & 1.260 & -0.003 \\
point 6 & 3.721 & 1.261 & -0.004 \\
point 7 & 1.073 & 0.516 & 0.013 \\
point 8 & 1.799 & 0.475 & 0.017 \\
point 9 & 2.715 & 0.592 & -0.009 \\
point 10 & 3.804 & 0.507 & -0.049 \\
\hline
\end{tabular}

Importantly, this camera view allows direct comparison to the measurements provided by the two radar systems mounted in parallel over channel c3. In Figure S12, the approximate measurement locations for velocity and water level are drawn. The same zones are provided as pixel ranges in Table S12. 


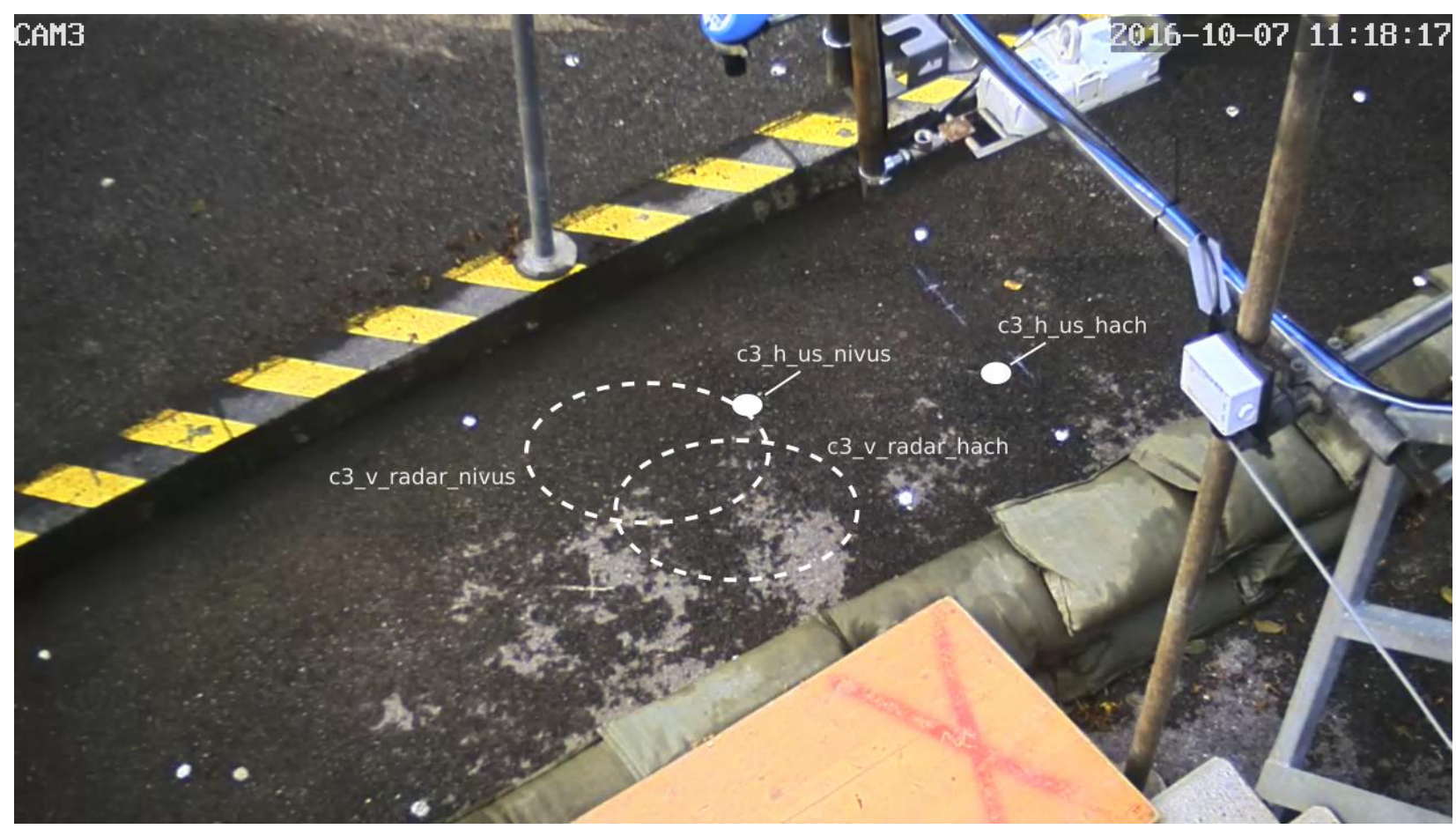

Figure S12: Approximate locations of radar and ultrasonic measurements in image of camera CAM3.

Table S12: Pixel ranges corresponding to measurement zones in channel c3.

\begin{tabular}{lllll}
\hline & $\mathbf{x}_{\min }$ & $\mathbf{x}_{\max }$ & $\mathbf{y}_{\min }$ & $\mathbf{y}_{\max }$ \\
\hline c3_v_radar_nivus & 453 & 671 & 328 & 451 \\
c3_v_radar_hach & 535 & 750 & 377 & 501 \\
c3_h_us_nivus & 641 & 644 & 339 & 354 \\
c3_h_us_hach & 863 & 885 & 311 & 326 \\
\hline
\end{tabular}

\subsubsection{Video camera for manhole opening c4 (c4_cam4_instar)}

Camera c4_cam4_instar is an INSTAR IN-5907HD positioned to detect water flowing in channel c4. 
ع: $0.27 @(2.818,-4.183,3.853),(1.02,0.12,0.15), 0.0099,-0.147,0,(\mathrm{x}),(\omega), \mathrm{f}, \mathrm{k} 1 \cdot 1 \mathrm{e} 6, \mathrm{k} 2 \cdot 1 \mathrm{e} 9$

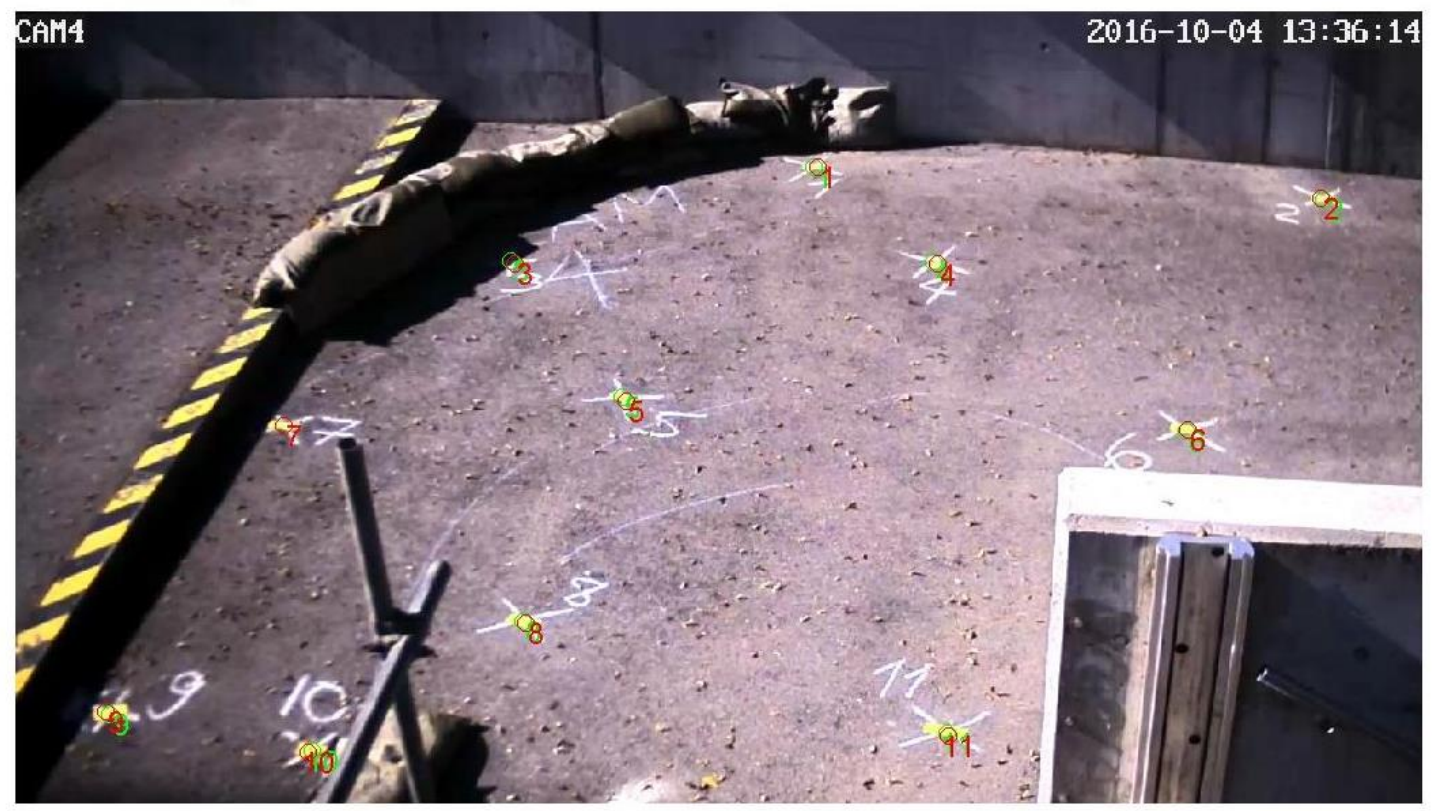

Figure S13: Calibration points and camera parameters of CAM4.

Table S13: Relative coordinates of camera CAM4 and calibration points

\begin{tabular}{llll}
\hline & $\mathbf{X}$ & $\mathbf{Y}$ & $\mathbf{Z}$ \\
\hline CAM4 & 2.82 & -4.18 & 3.85 \\
point 1 & 1.617 & 4.265 & -0.003 \\
point 2 & 3.963 & 4.313 & -0.004 \\
point 3 & 0.497 & 3.139 & 0.004 \\
point 4 & 2.243 & 3.358 & -0.001 \\
point 5 & 1.204 & 2.111 & 0.001 \\
point 6 & 3.270 & 2.175 & -0.001 \\
point 7 & -0.021 & 1.739 & 0.022 \\
point 8 & 1.183 & 0.736 & 0.005 \\
point 9 & 0.000 & 0.007 & 0.039 \\
point 10 & 0.706 & -0.009 & 0.016 \\
point 11 & 2.545 & 0.387 & -0.011 \\
\hline
\end{tabular}




\subsubsection{Video camera for basement s6 (s6_cam5_instar)}

Camera s6_cam5_instar is an INSTAR IN-5907HD positioned to detect water accumulating in the basement s6. On 6/10/2016 a marked rod was placed in the manhole in order to visually quantify the rise and fall of water. The dimensions of the rod are provided in the additional material.

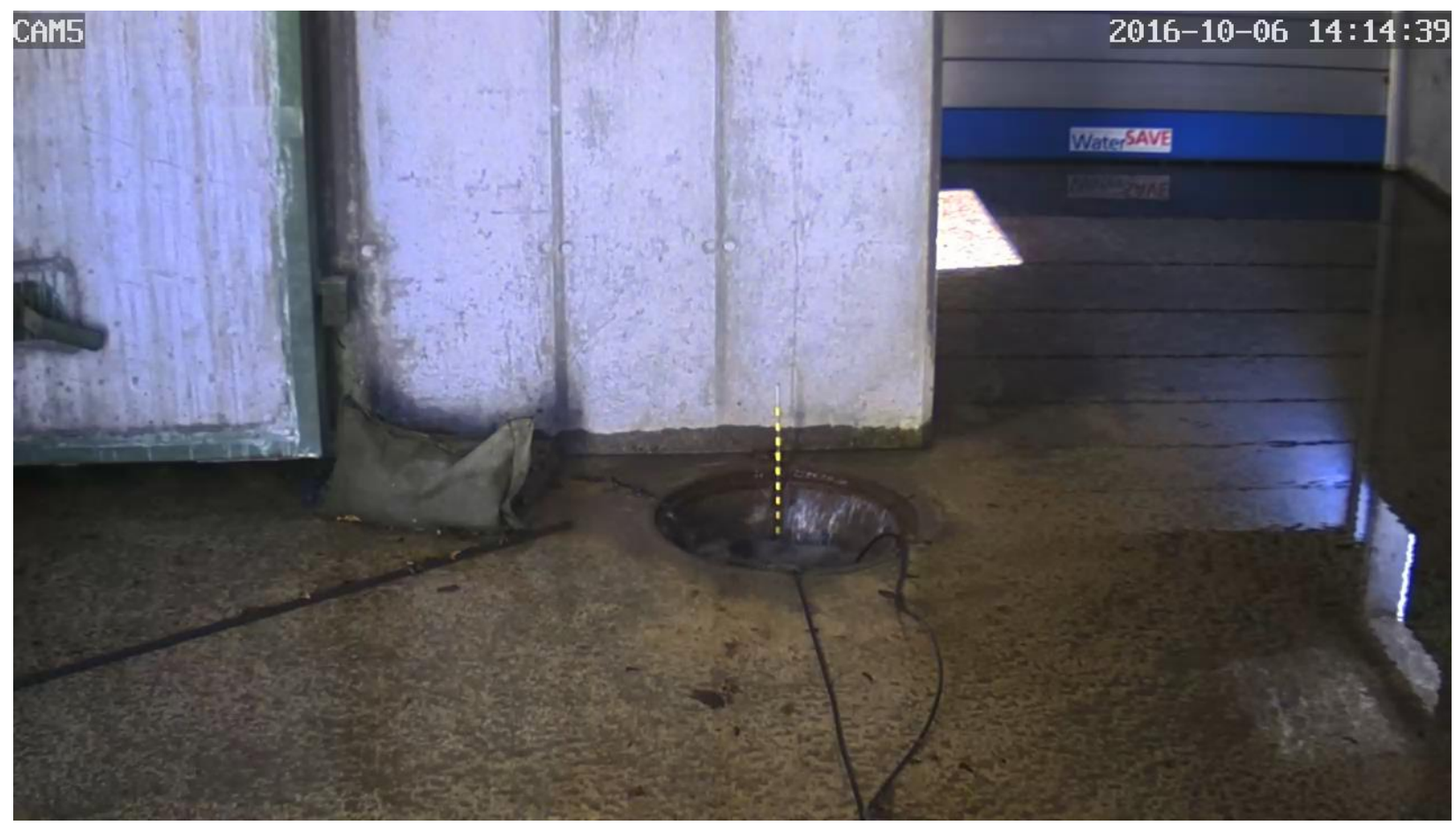

Figure S14: View from CAM5 of manhole m3, with ruler pole system emerging from hole. 


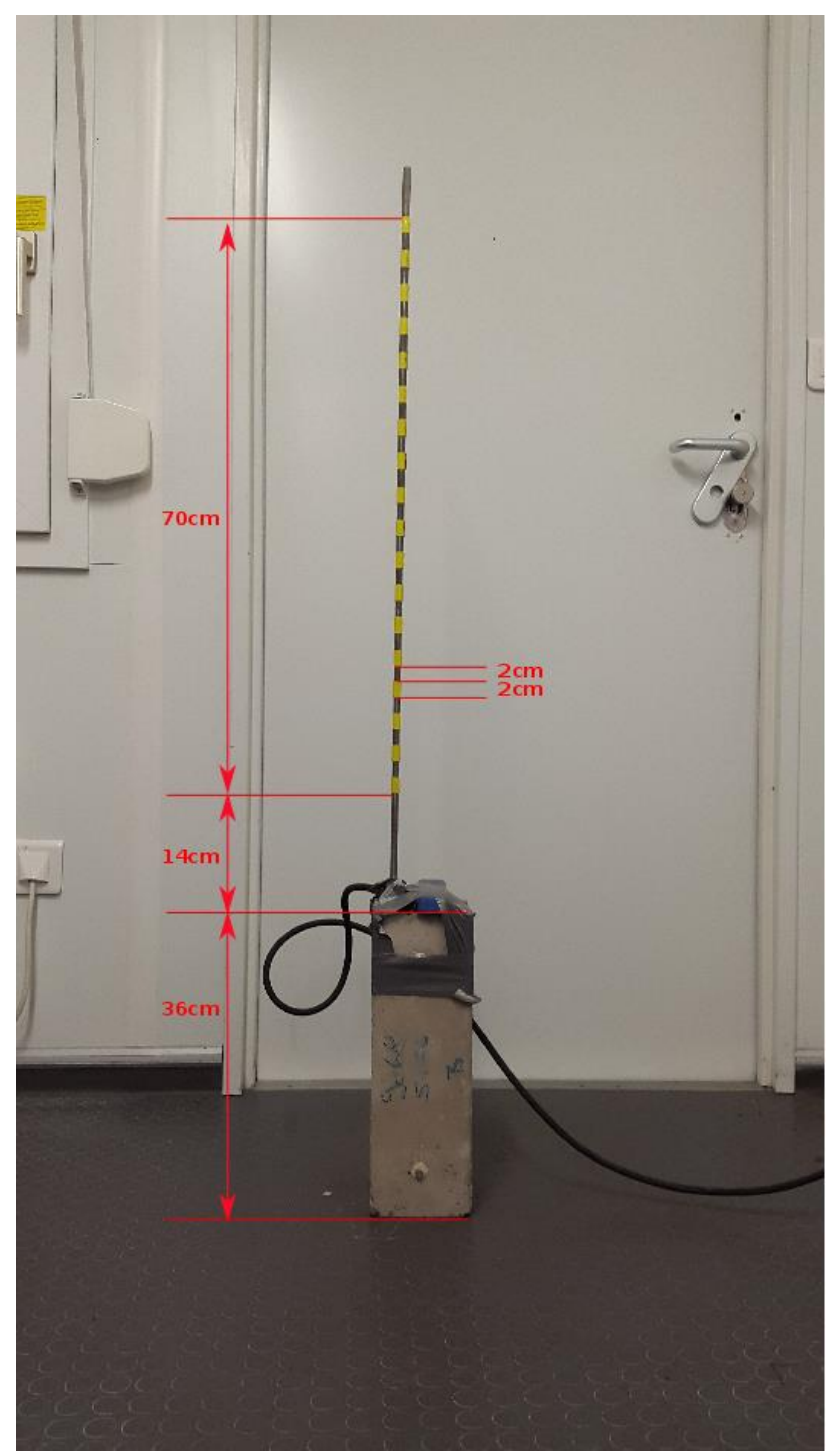

Figure S15: Dimensions of ruler pole system placed in manhole m3. The pressure probe m3_h_p_hach can be seen in blue at the top of the cement block.

\subsection{Pressure sensors}

Waterpilot FMX21 barometric probes from Endress+Hauser were used to record the water level in manholes m1, m2, and m3. The measurements were logged with three Minilog RDL10, meant for operational situations, which had to be supplemented with imaging devices in order to obtain a higher recording frequency (as for p1_q_mid_endress). In contrast with the solution implemented for p1_q_mid_endress, the imaging devices could not record the display of the sensor but had to record the displays of the Minilog RDL10 logger, on which instantaneous values appear intermittently instead of constantly. Additionally, only one Logitech c920 webcam and one COOLPIX AW100 were used to record all three logger displays. The data from the different logging systems are named in the following way: 
- $\quad \mathbf{m}[\mathbf{1 , 2 , 3}] \mathbf{h} \_\mathbf{p} \_$endress_minilog: Minilog RDL10 logger, saves one value every minute which is the average water level of the past 60 seconds

- $\quad \mathbf{m}[\mathbf{1 , 2 , 3}]$ _h_p_endress _logi: one-second interval images from a Logitech c920 webcam, installed on 6/10/2016

- $\mathbf{m}[\mathbf{1 , 2 , 3}] \mathbf{h} \_\mathbf{p} \_$endress _coolpix: high-definition video recordings with a COOLPIX AW100 point-and-shoot camera.

\subsection{1 m1_h_p_endress}

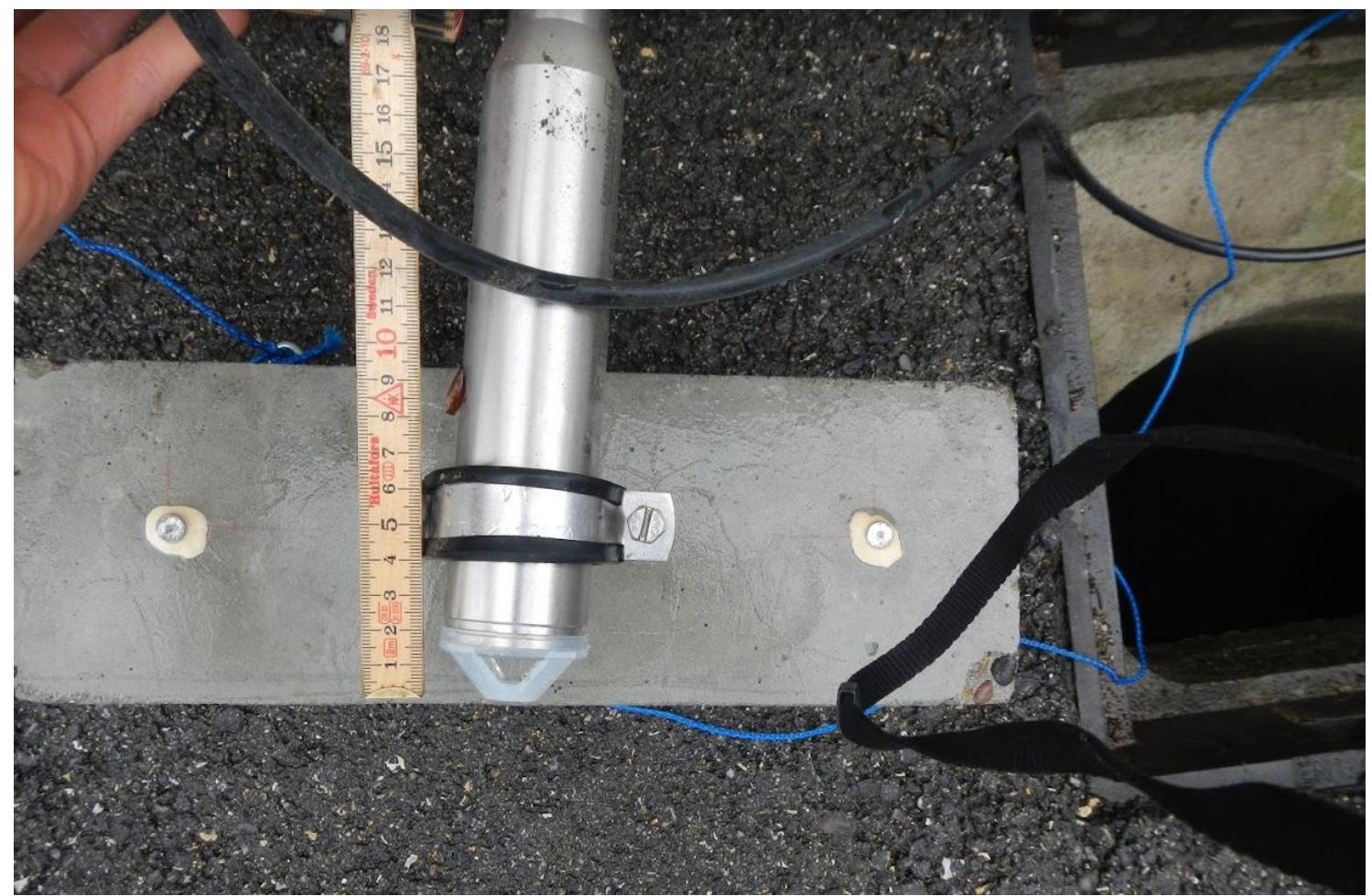

Figure S16: Sensor m1_h_p_endress that was placed in manhole m1.

By post-analyzing the data from this sensor, we were able to determine that the reference elevation of the probe was 418.42 meters above sea level. 


\subsection{2 m2_h_p_endress}
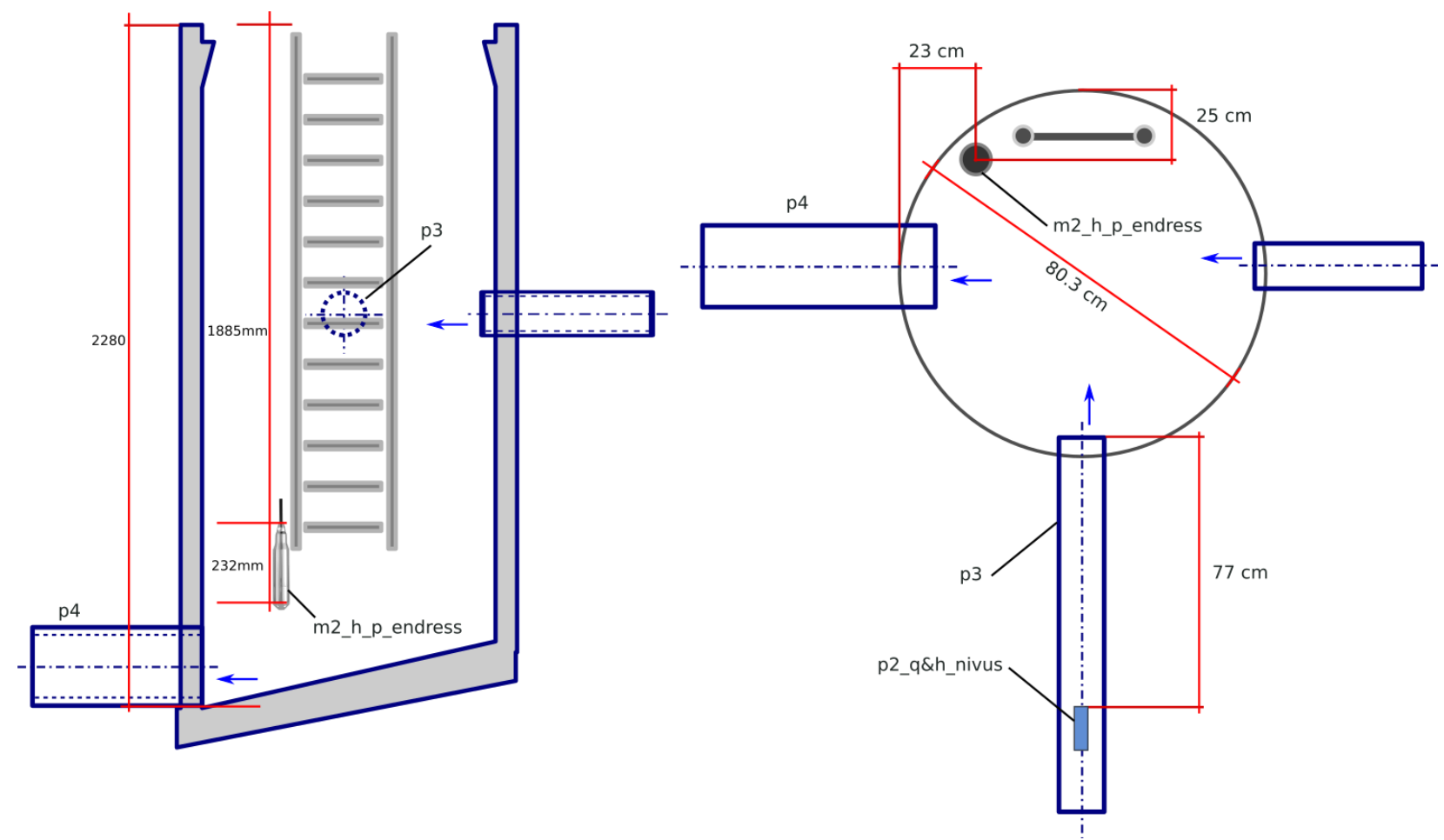

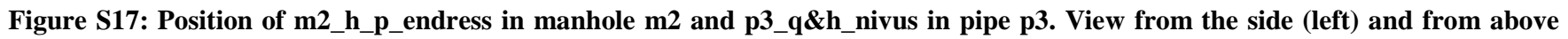
(right)

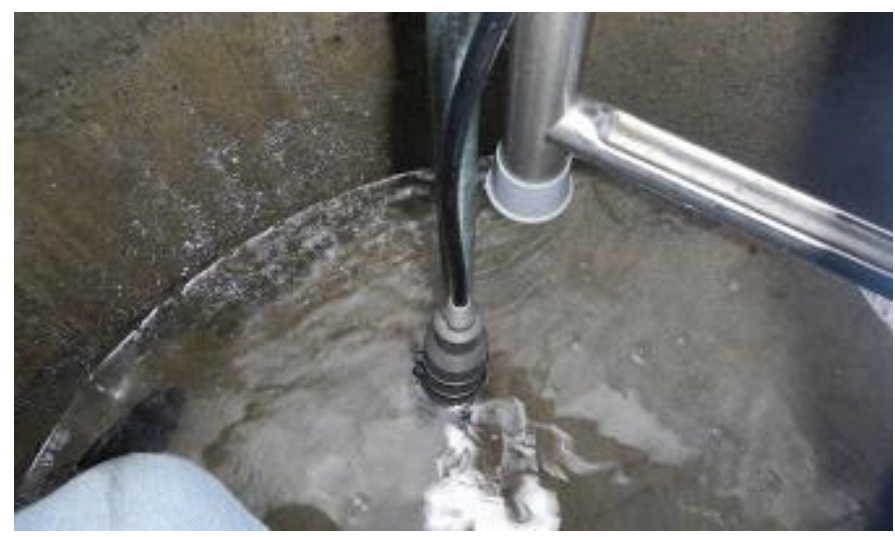

Figure S18: Installation of m2_h_p_endress in manhole m2. 


\subsection{3 m3_h_p_endress and $\mathbf{m} 3 \_h \_p \_h a c h$}

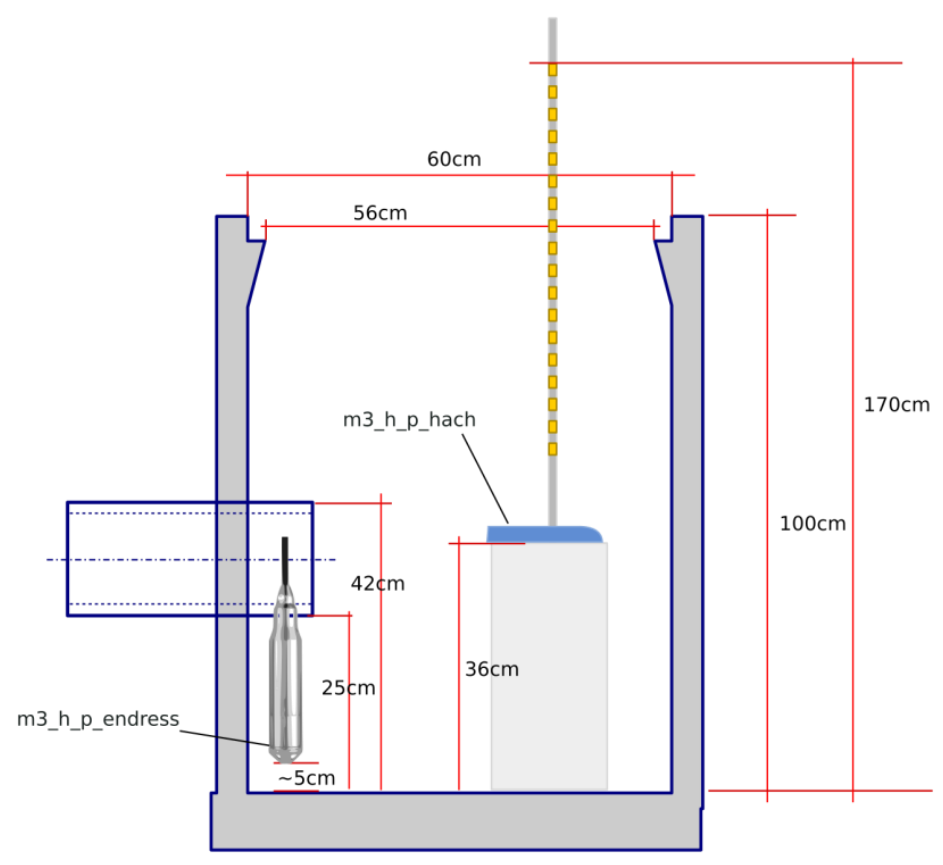

Figure S19: Placement of sensors m3_h_p_endress and m3_h_p_hach in manhole m3.

\subsubsection{Barometric water level sensor in manhole $\mathbf{m 3}$ (m3_h_p_hach)}

A Hach AV9000 was used in manhole m3 to measure the water level in the basement of the house. Like the other Hach device, the logging frequency of m3_h_p_hach was one minute. 


\subsection{Temperature probes at opening r3 of manhole $\mathbf{m} 2\left(r 3 \_t \_o n s e t \_1 / 2 / 3 / 4\right)$}

Four Onset TMC6-HD temperature probes were placed at the opening $\mathrm{r} 3$ of manhole $\mathrm{m} 2$ in order to detect manhole overflows (Figure S20).

- r3_t_onset_1 is located within the manhole, $21.5 \mathrm{~cm}$ below ground level;

- $\quad$ 33_t_onset_2 is located within the manhole, $7.5 \mathrm{~cm}$ below ground level;

- $\quad \mathrm{r} 3$ _t_onset_3 is located $3 \mathrm{~cm}$ away from the edge of the manhole, $2.5 \mathrm{~cm}$ above ground level;

- r3_t_onset_4 is located in a place where it was not supposed to get wet, in the shade, in a

The data was logged at one second intervals using a Onset HOBO U12-006 data logger.

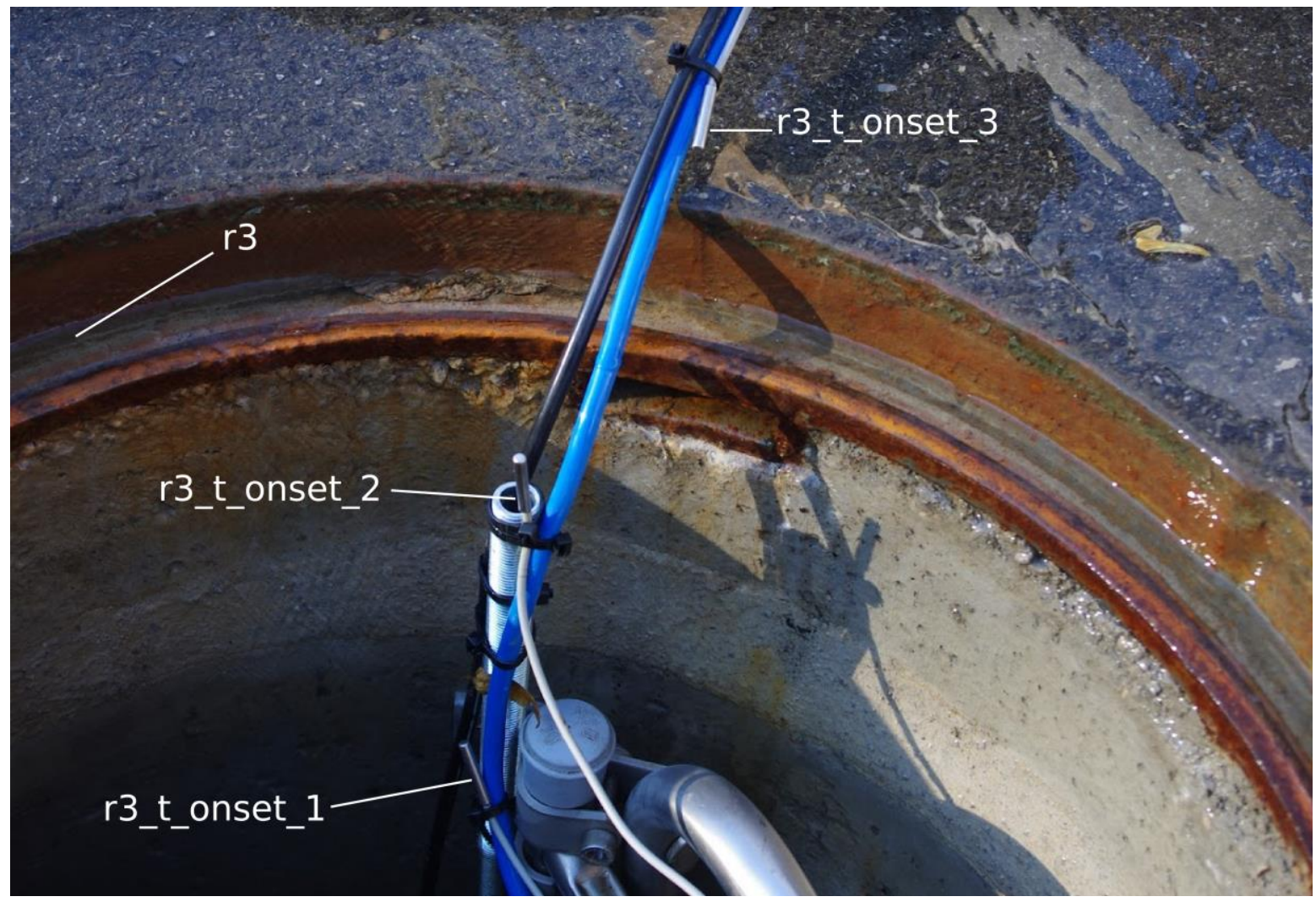

Figure S20: temperature sensors r3_t_onset at the orifice $\mathbf{r} 3$ of manhole m2. Sensor r3_t_onset_4 is situated away from the orifice, in the shade. 


\subsection{Magnetic inductive flow sensor in pipe p1 (p1_q_mid_endress)}

This Endress+Hauser Proline Promag 53P device was installed in an extension at the entry of pipe p1, in the reservoir s1 (Figure S21). It provides very accurate readings of flow at a high frequency. The extension was necessary because of the geometry of the reservoir and to guarantee a sufficient stabilization of the flow. Because the logger used with this device for operational purposes only logs a mean value every minute, we had to install camera systems to record the display of the logger (Figure S22).

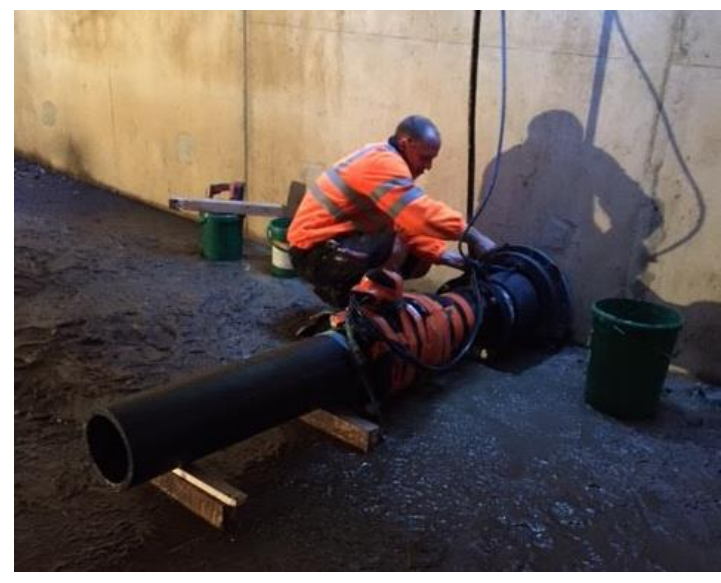

Figure S21: Installation of p1_q_mid_endress in the reservoir s1.
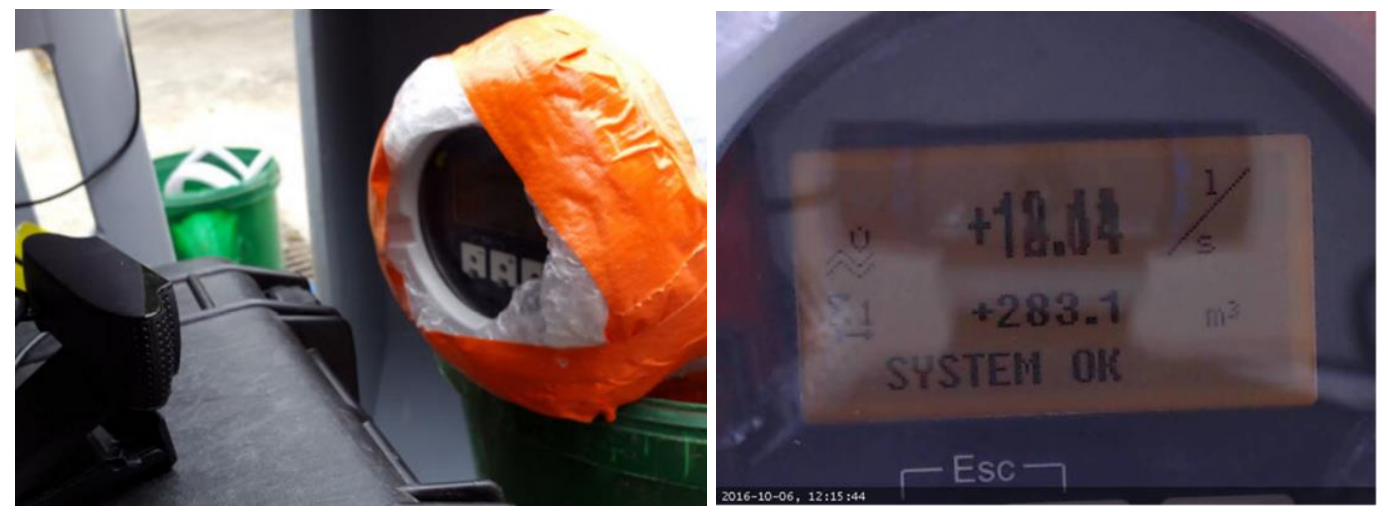

Figure S22: setup and example image for alternative logging of p1_q_mid_endress

The data from the different logging systems are named in the following way:

- p1_q_mid_endress_minilog: Minilog RDL10 logger, saves one value every minute which is the average flow of the past 60 seconds

- p1_q_mid_endress_logi: One-second interval images from a Logitech c920 webcam, installed on 6/10/2016 
2.5 Water level and flow velocity in open channel c3 (c3_v_radar_nivus, c3_h_us_nivus, c3_v_radar_hach and c3_h_us_hach)

Two systems were installed in parallel to measure surface water velocity and level in the channel c3 (Figure S23). The first system is a Nivus OFR Radar sensor (for water velocity) and NivuCompact (ultrasound for water level) while the second is a Hach Flodar that combines radar and ultrasound in one device. The velocity logged by both devices is a bulk velocity and not the surface velocity. The Nivus system logged data at 5 second intervals while the Hach system logged data at 1 minute intervals.

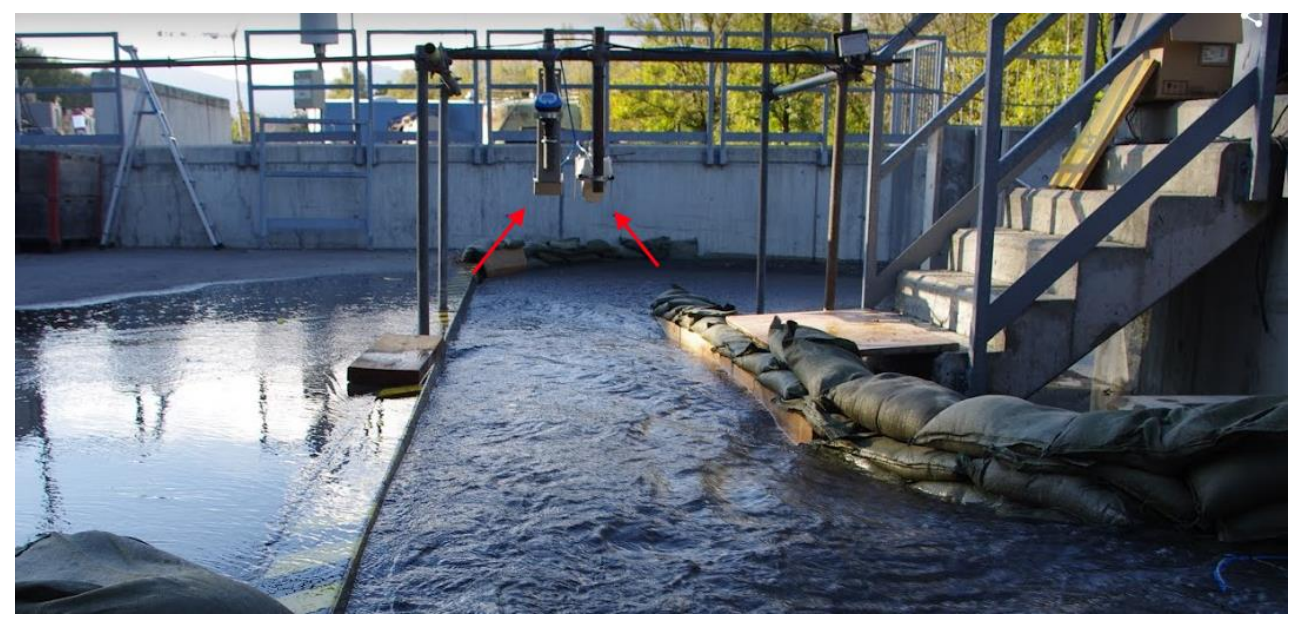

Figure S23: Two radar systems mounted above channel c3: Nivus (left) and Hach (right)

The Hach Flodar has a measurement range of $0.23 \mathrm{~m} / \mathrm{s}-6.1 \mathrm{~m} / \mathrm{s}$ for the flow velocity and a $0-1.524 \mathrm{~m}$ range for the water level. For stationary flow conditions, a measurement error of $+/-5 \%$ can be expected, but this will be larger in non-stationary conditions. The Nivus OFR Radar sensor has a velocity measurement range of $-1 \mathrm{~m} / \mathrm{s}$ to $6 \mathrm{~m} / \mathrm{s}$, and water level range of $0-5$ m. The measurement error can be expected to be around $2 \%$ for velocity and $2-5 \%$ for flow, depending on hydraulic conditions. However, we can expect a greater error because of the low water level (around $5 \mathrm{~cm}$ ) and observed drift in water level measurement.

\subsection{Ultrasonic flow sensors}

The ultrasonic flow sensors used were Nivus CSM-V1D0 devices. The sensor is a small format sensor that combines an ultrasonic velocity profile measurement with a pressure-based water level sensor.

\subsubsection{Ultrasonic flow sensor in pipe p2 (p2_q_us_nivus and p2_h_p_nivus)}

The first sensor was installed in pipe p2 to measure flow (p2_q_us_nivus). However, the proximity of the sensor to manhole $\mathrm{m} 2$ means that the water level estimation (p2_h_p_nivus) at the sensor also tells us something about the water level in the manhole $\mathrm{m} 2$ (Figure S17). The data was logged using a Nivus PCM Pro at 5-second intervals. 


\subsubsection{Ultrasonic flow sensor in pipe p6 (p6_q_us_nivus and p6_h_p_nivus)}

The second sensor was installed in pipe p6 (see Figure S28) to measure flow (p6_q_us_nivus). Pressure was also measured (p6_h_p_nivus). The data was logged using a Nivus PCM Pro at 5-second intervals.

\subsection{Ultrasonic water level sensors}

\subsubsection{Ultrasonic water level sensors in reservoir $\mathbf{s 1}$ (s1_h_us_maxbotix)}

Two Maxbotix MB7369 ultrasonic water level sensors s1_h_us_maxbotix_1 and s1_h_us_maxbotix_2 were installed in the reservoir s1 (Figure S24). However, because an additional water level measurement was required in s3, s1_h_us_maxbotix_2 was removed on the 6/10/2016 in the morning. The readings of these sensors were logged using an in-house LabView program running on a laptop computer. The sensors provide around 6 readings per second that are neither calibrated nor adjusted for temperature changes.
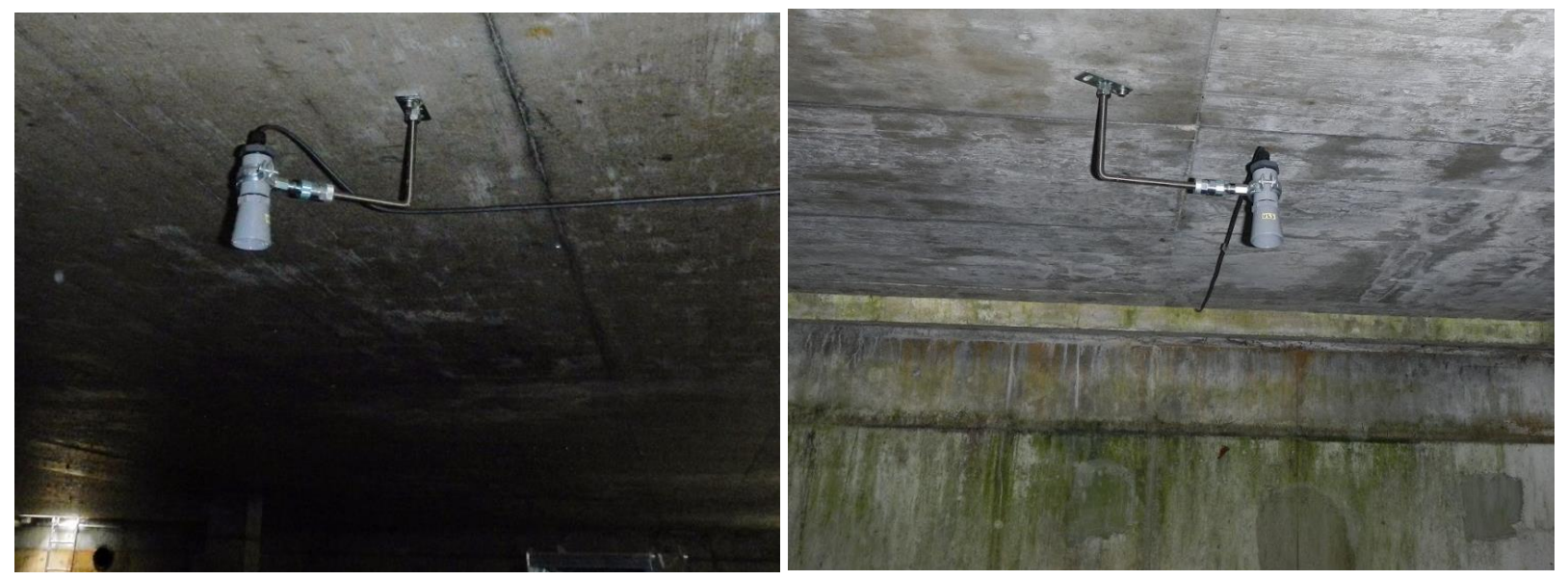

Figure S24: Ultrasonic water level sensors mounted in the reservoir s1: s1_h_us_maxbotix_1 (left) and s1_h_us_maxbotix_2 (right) 


\subsubsection{Ultrasonic water level sensor in reservoir s3 (s3_h_us_maxbotix)}

A Maxbotix MB7369 ultrasonic water level sensor s3_h_us_maxbotix was installed in the reservoir s3 on 6/10/2016 in the morning. The sensor provides around 6 readings per second that are neither calibrated nor adjusted for temperature changes. The readings were logged by an in-house LabView program running on a laptop computer.

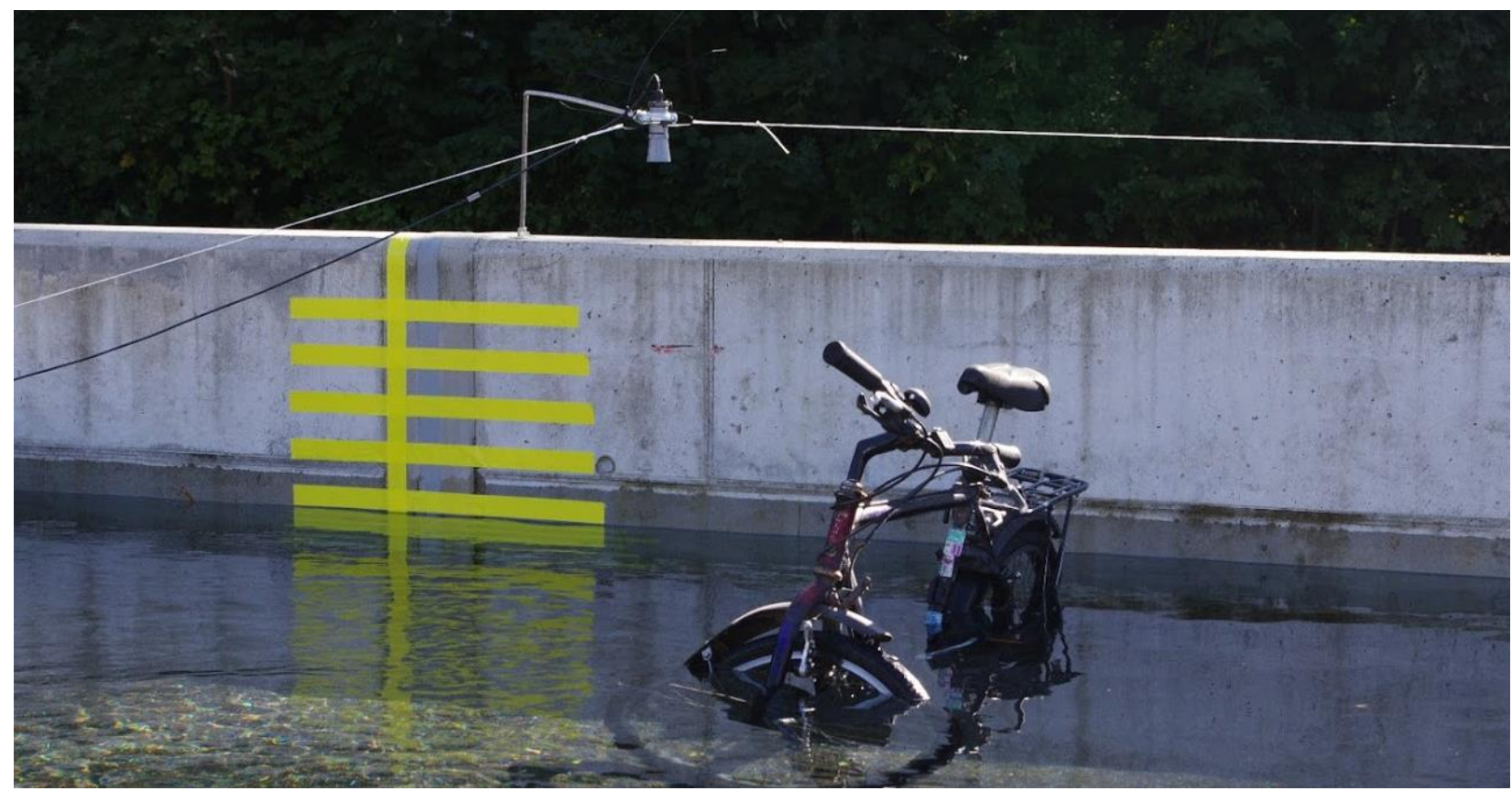

Figure S25: Photo of sensor s3_h_us_maxbotix above storage area s3.

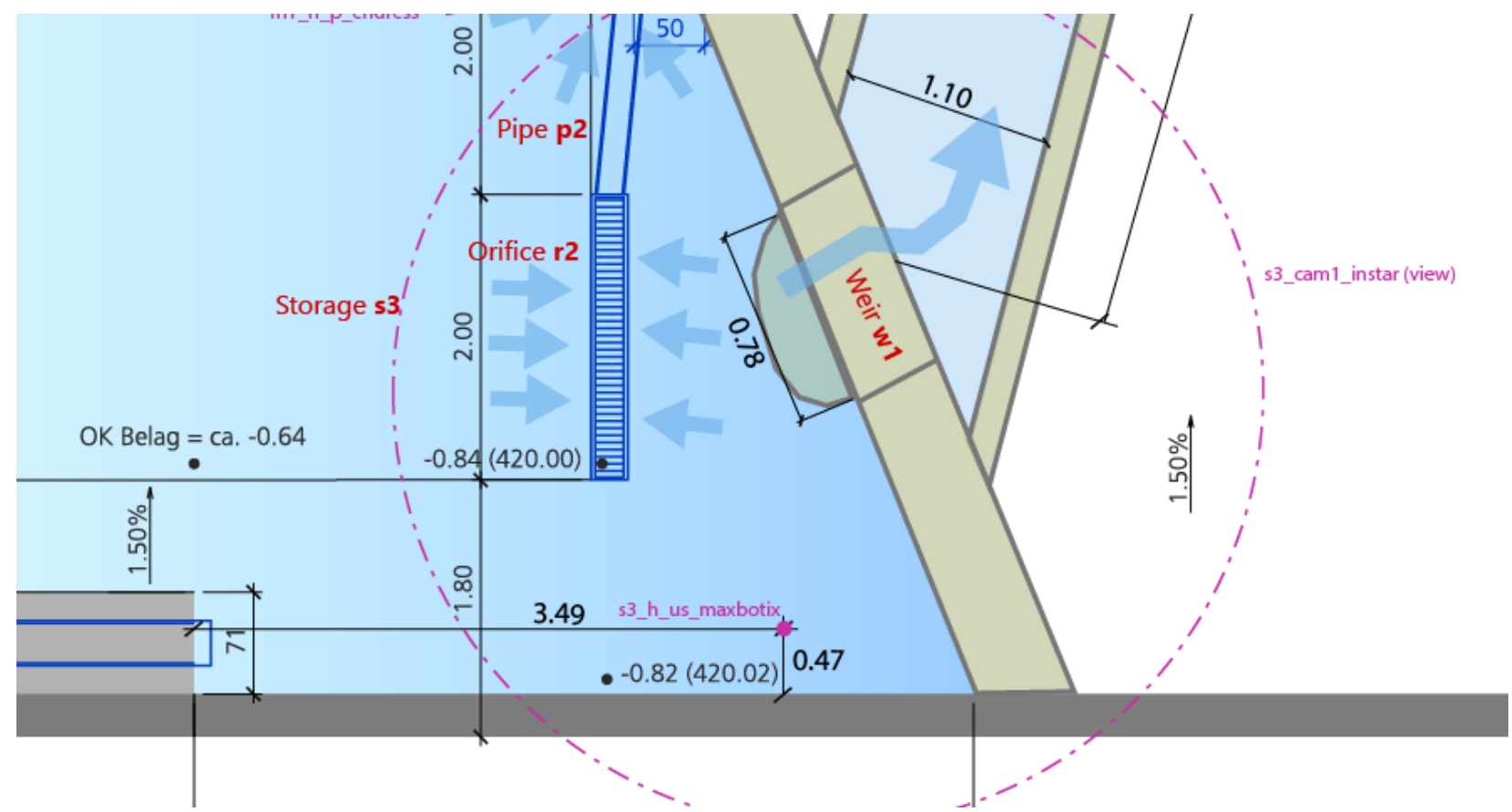

Figure S26: Sketch describing location of s3_h_us_maxbotix in storage area s3. 


\subsection{3 s6_h_us_maxbotix}

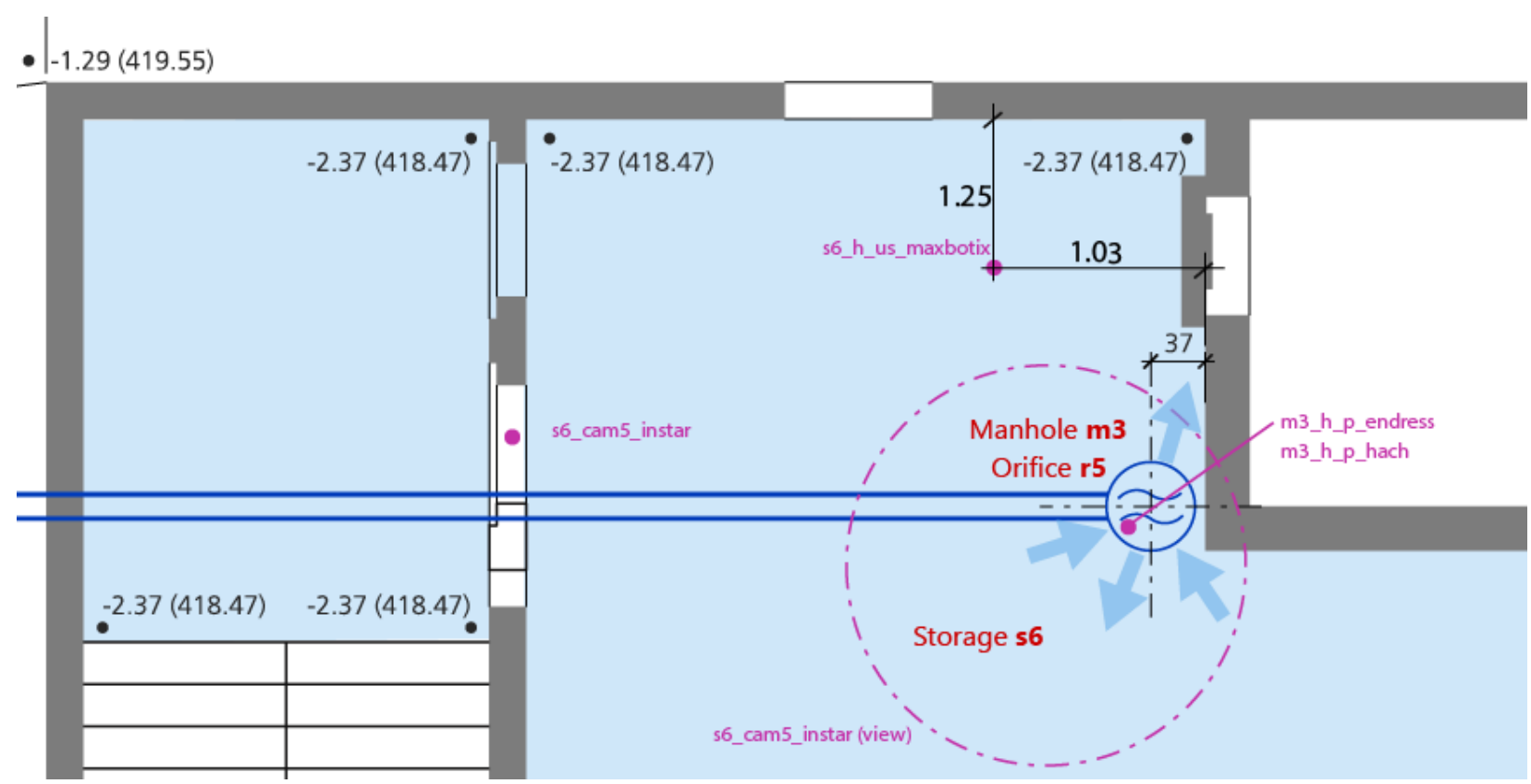

Figure S27: Placement of sensor s6_h_us_maxbotix in the basement of the house.

\subsubsection{Ultrasonic water level measurement in exit shaft (s5_h_us_maxbotix_1 and s5_h_us_maxbotix_2)}

A Maxbotix MB7369 ultrasonic water level sensor was installed in exit shaft s5, but it had to be moved from its initial location (where it was called s5_h_us_maxbotix_1) because the measurement was disturbed by water falling into the shaft. In its new location, the sensor carries the name s5_h_us_maxbotix_2.
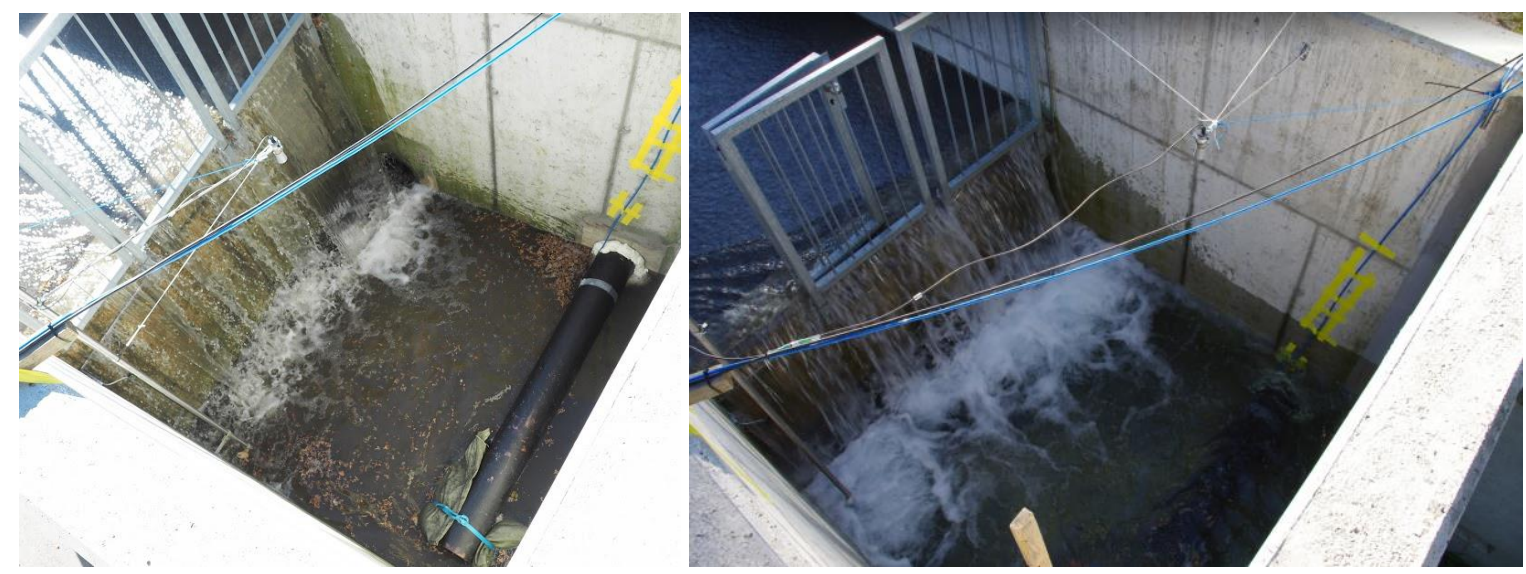

Figure S28: locations of ultrasonic sensor as s5_h_us_maxbotix_1 (left) and s5_h_us_maxbotix_2 (right). Pipe p6 is visible at the bottom of the shaft. 


\subsection{Shaft s5, pipe p6, and sensors p6_q\&h_p_nivus}

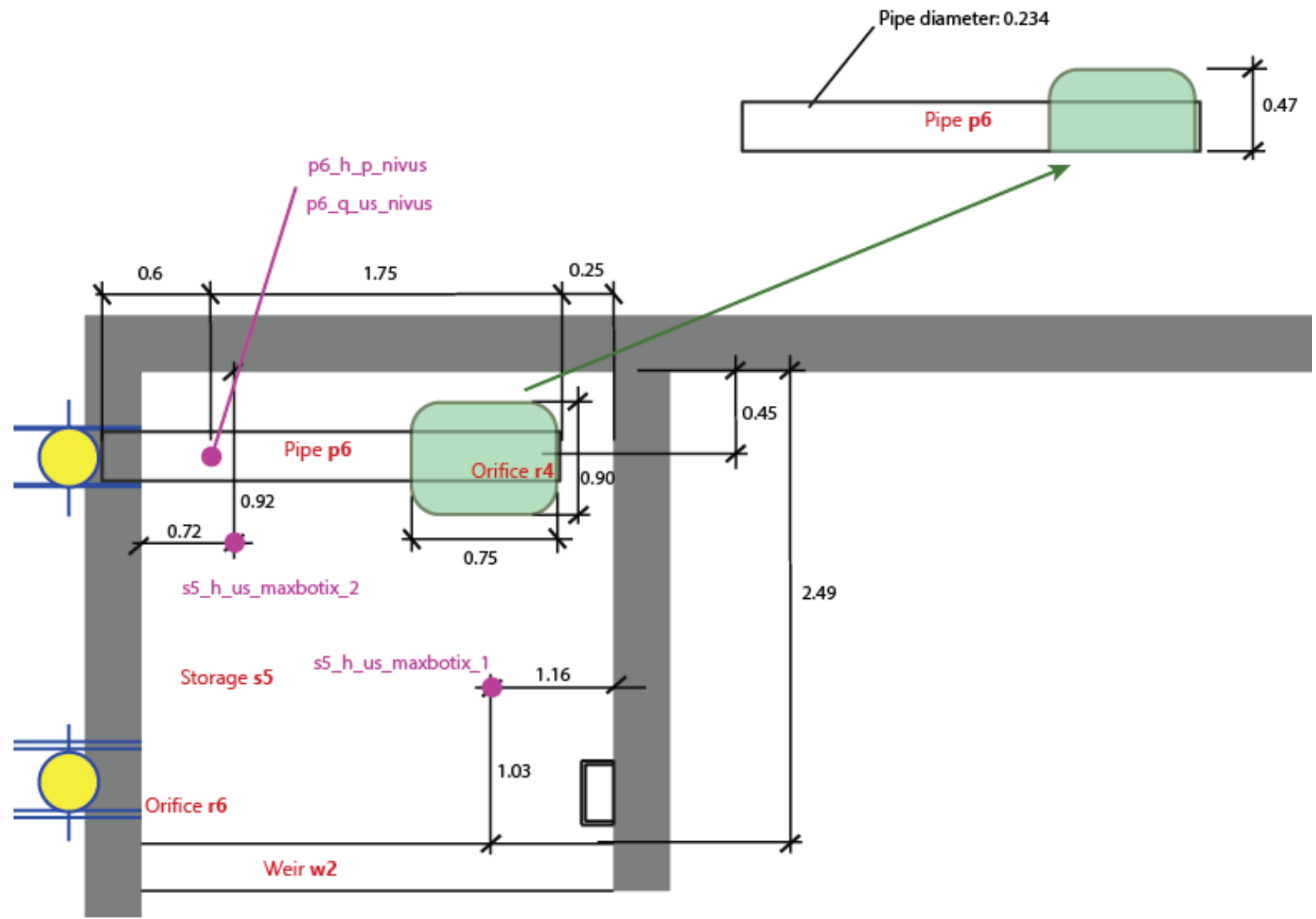

Figure S29: Shaft s5, containing pipe p6.

\section{Data preprocessing}

\subsection{Standard processing steps}

- Consolidation: Data for a single sensor but stored in multiple source files are consolidated into a single file. The paths to the source files are contained in the metadata.csv file. The specific formatting of each source file is specified in metadata.csv file.

- Sorting: Since the data is consolidated from multiple files, each data entry must be sorted in chronological order.

- Formatting: Each data logger uses a particular formatting system for the csv formatting, the date and time, and for null values. These formats are homogenised according to the user preferences defined in settings.py. However, all null values are simply removed from the data.

- Offsetting: Ultrasonic water level sensors measure the gap between the water and the sensor. To obtain the water level, this value has to be offset by the distance between the ground and the sensor (ground_level value in metadata.csv). 
- Time shifting: Delays and time zone differences of logger clocks are corrected (time_shift in metadata.csv).

- Removal of extreme values: Impossible values such as negative water levels and extremely large values due to OCR misreading of the sensor displays are adjusted or removed, respectively (max_valid_value and floor_value in metadata.csv). Some data loggers, like those from Nivus and Hach, remove impossible values automatically.

- Segmentation of data by experiment: The processed data can be exported either grouped by experiment, for modelling, or ungrouped, for viewing and exploring. The data grouped by experiment are cropped to exclude time between experiments, e.g., when the system is flushed. Export grouping preferences are set by the export_selection option in settings.py.

- Formatting for time series database: For viewing and exploring the data, we recommend using CrateDB (https://crate.io/) for a time series database and Grafana (http://grafana.org/) as a graphical dashboard. To import the data into CrateDB, the data must be formatted in a JSON-like fashion. If the write_crateDB option is set to True, then the data will be written in the required JSON format as well.

\subsection{Reading sensor display images with optical character recognition}

Because of the low logging frequency of the minilog data loggers, which was only discovered in the middle of the experiment campaign, high frequency measurements for sensors p1_q_mid_endress, m1_h_p_endress, m2_h_p_endress, and m3_h_p_endress were only possible by taking images of the sensor or logger displays. These images are provided in the floodX Data Logger Images package (see example in Figure S30).

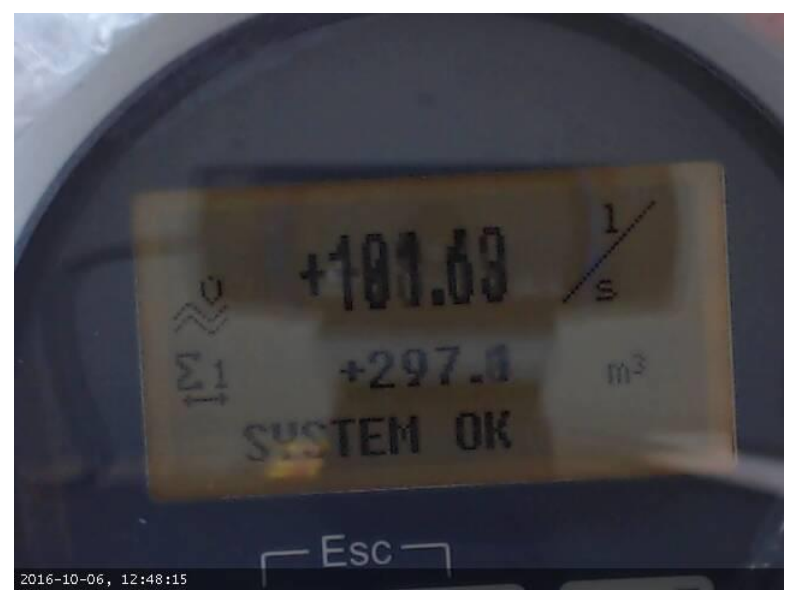

Figure S30: Example image of the display of the discharge sensor in pipe p1.

To process the images into text data, the preprocessing script makes use of a well-known implementation of optical character recognition (OCR) called tesseract-ocr ${ }^{1}$ (Smith et al., 2007), which is called from Python with a wrapper (pytesseract) ${ }^{2}$. The Python script first clips out the area(s) of interest from the image before processing it with OCR. Since the position(s) of the

\footnotetext{
${ }^{1}$ Smith, R., Smith, R. and Inc, G.: An overview of the Tesseract OCR Engine, PROC. 9TH IEEE INTL. CONF. Doc. Anal. Recognit. (ICDAR, 629--633 [online] Available from: http://citeseerx.ist.psu.edu/viewdoc/summary?doi=10.1.1.308.445 (Accessed 16 December 2016), 2007.

${ }^{2}$ https://pypi.python.org/pypi/pytesseract
} 
display(s) sometimes changed between recording sessions, the images are grouped by session and are associated with a settings file that indicates the bounding box and rotation of the sensors.

Because the image exposure was sometimes too large, some of the images are an overlay of two values on the display. In some cases, this causes the OCR algorithm to falsely interpret the value and an error is produced. In some cases, this error is very great and the outlier value can be removed with a simple threshold during data preprocessing. In the future, more advanced filters could be implemented for the data.

While the tesseract-ocr solution is effective for the images of p1_q_mid_endress to log water flow in pipe p1, it does not work with images with the $m[1 / 2 / 3]$ _h_p_endress for water levels at manholes, possibly because of the image quality and the small size of the displays that disturb the image segmentation process. No solution for reading pressure measurement images was invested into, since the variation of water level at the manholes is not as rapid as it is for flow in pipe p1. Just in case, additional image material for the pressure sensors has been provided in the form of HD video material (floodX Data Logger Videos package).

\subsection{Video and image data}

Due to the nature of the video data, it is not possible to modify it in a satisfactory way, e.g. to correct time stamps. For this reason, the temporal shifts of the cameras for each recording session are provided in tabular format (Table S14). (Positive values indicate that the video time is ahead of the reference time)

Table S14: Temporal offset of cameras during the last two days of the floodX experiments.

\begin{tabular}{llllll}
\hline recording session & cam1 & cam2 & cam3 & cam4 & cam5 \\
\hline 161005A & $00: 00: 03$ & $00: 00: 00$ & $00: 00: 09$ & $-00: 00: 04$ & $-00: 00: 07$ \\
161005B & $00: 00: 03$ & $00: 00: 00$ & $00: 00: 09$ & $-00: 00: 04$ & $-00: 00: 07$ \\
161006A & $00: 00: 03$ & $00: 00: 00$ & $00: 00: 10$ & $-00: 00: 03$ & $-00: 00: 10$ \\
161006B & $00: 00: 02$ & $00: 00: 00$ & $00: 00: 09$ & $-00: 00: 04$ & $-00: 00: 11$ \\
161007A & $-00: 00: 01$ & $00: 00: 00$ & $00: 00: 07$ & $-00: 00: 11$ & $-00: 00: 14$ \\
\hline
\end{tabular}




\section{Tables of hydraulic components and datasources}

Table S15: Labeling of hydraulic components.

\begin{tabular}{|c|c|c|}
\hline Label & Type & Description \\
\hline c1 & Open channel & ramp leading to pond $\mathrm{n} 1$ \\
\hline c2 & Open channel & open channel leading from dam \\
\hline c3 & Channel & Laminar flow channel where radars are placed \\
\hline c4 & Channel & Variable width channel approaching 2D flow \\
\hline m1 & Manhole & manhole to which drain inlets in dam \\
\hline $\mathbf{m} 2$ & Manhole & manhole in front of house, which overflows \\
\hline $\mathbf{m 3}$ & Manhole & Manhole in basement of house \\
\hline s1 & Storage & Main reservoir \\
\hline s2 & Storage & Shaft into which $\mathrm{p} 1$ empties, and which leads to ramp \\
\hline $\mathbf{s 3}$ & Storage & Pond formed by dam after ramp, contains bicycle. Drained by $\mathrm{r} 1$ and $\mathrm{r} 2$ \\
\hline s4 & Storage & Pond around overflow manhole \\
\hline s5 & Storage & Exit shaft \\
\hline s6 & Storage & basement of house, that can be flooded \\
\hline p1 & Pipe & connects reservoir to facility, up to valve \\
\hline p2 & Pipe & pipe connecting $\mathrm{r} 1$ to $\mathrm{m} 1$ \\
\hline p3 & Pipe & pipe connecting $\mathrm{m} 1$ to $\mathrm{m} 2$ \\
\hline p4 & Pipe & pipe linking $\mathrm{m} 2$ to distribution pipe $\mathrm{p} 5$ \\
\hline p5 & Pipe & distribution pipe allowing water to communicate between pipes of the sewer network \\
\hline p6 & Pipe & Pipe containing pipe profiler, for measuring flow exiting system \\
\hline p7 & Pipe & Pipe leading from distribution pipe $\mathrm{p} 5$ to manhole in basement $\mathrm{m} 3$ \\
\hline p8 & Pipe & Pipe draining the facility \\
\hline r1 & Orifice & long sewer inlet covered with grating \\
\hline r2 & Orifice & rectangular sewer inlet with a spring-action grating \\
\hline r3 & Orifice & Manhole opening of $\mathrm{m} 2$, leading to $\mathrm{n} 4$ \\
\hline
\end{tabular}




\begin{tabular}{lll}
\hline $\mathbf{r 4}$ & Orifice & Orifice of pipe containing pipe profiler \\
$\mathbf{r 5}$ & Orifice & Manhole opening of $\mathrm{m} 3$, in basement \\
$\mathbf{r 6}$ & Orifice & orifice between $\mathrm{n} 5$ and $\mathrm{p} 9$ \\
$\mathbf{v 1}$ & Valve & main valve that controls how much water enters the facility \\
$\mathbf{v 2}$ & Valve & valve between $\mathrm{p} 4$ and $\mathrm{p} 5$, closed during experiments but opened to empty out water from \\
$\mathbf{v 3}$ & Valve & Valve between $\mathrm{p} 5$ and $\mathrm{p} 7$, left open during all experiments \\
$\mathbf{v 4}$ & Valve & Valve controlling water exiting system \\
$\mathbf{w 1}$ & Weir & weir of dam that forms $\mathrm{n} 3$ \\
$\mathbf{w 2}$ & Weir & curb delimiting $\mathrm{c} 2$ and $\mathrm{n} 4$ \\
$\mathbf{w 3}$ & Weir & waterfall from surface to exit shaft $\mathrm{n} 5$ \\
$\mathbf{w 4}$ & Weir & weir between shaft $\mathrm{n} 2$ and ramp \\
\hline
\end{tabular}

Table S16: List of datasources involved in floodX experiments.

\begin{tabular}{|c|c|c|c|c|c|c|c|c|c|}
\hline Location & datasource & Sensor & $\begin{array}{l}\text { Measurement } \\
\text { principle }\end{array}$ & Logger & Parameter & Unit & $\begin{array}{l}\text { Interval } \\
\text { Resolution }\end{array}$ & l & Installation \\
\hline s1 (reservoir) & s1_h_us_maxbotix_1 & Maxbotix MB7369 & Ultrasonic & Labview script & $\mathrm{d}$ & $\mathrm{mm}$ & $6 / \mathrm{sec}$ & & 03.10 .16 \\
\hline s1 (reservoir) & s1_h_us_maxbotix_2 & Maxbotix MB7369 & Ultrasonic & Labview script & $\mathrm{d}$ & $\mathrm{mm}$ & $6 / \mathrm{sec}$ & & 03.10 .16 \\
\hline $\begin{array}{l}\text { p1 (pipe } \\
\text { reservoir) }\end{array}$ & p1_q_mid_endress_minilog & $\begin{array}{l}\text { Endress+Hauser } \\
\text { Promag 53P }\end{array}$ & $\begin{array}{l}\text { Inductive magnetic } \\
\text { field }\end{array}$ & Minilog RDL10 & Q & $1 / \mathrm{s}$ & $1 \mathrm{~min}$ & & 03.10 .16 \\
\hline $\begin{array}{l}\text { p1 (pipe } \\
\text { reservoir) }\end{array}$ & p1_q_mid_endress_coolpix & $\begin{array}{l}\text { Endress+Hauser } \\
\text { Promag 53P }\end{array}$ & $\begin{array}{l}\text { Inductive magnetic } \\
\text { field }\end{array}$ & $\begin{array}{l}\text { COOLPIX } \\
\text { AW100 }\end{array}$ & Q & $1 / \mathrm{s}$ & $<1 \mathrm{sec}$ & & 03.10 .16 \\
\hline $\begin{array}{l}\text { p1 (pipe from } \\
\text { reservoir) }\end{array}$ & p1_q_mid_endress_logi & $\begin{array}{l}\text { Endress+Hauser } \\
\text { Promag 53P }\end{array}$ & $\begin{array}{l}\text { Inductive magnetic } \\
\text { field }\end{array}$ & Logitec c920 & Q & $1 / \mathrm{s}$ & $1 \mathrm{sec}$ & & 03.10 .16 \\
\hline s3 (artificial lake) & s3_h_us_maxbotix & Maxbotix MB7369 & Ultrasonic & Labview script & $\mathrm{d}$ & $\mathrm{mm}$ & $<1 \mathrm{sec}$ & & 05.10 .16 \\
\hline m1 (manhole in lake) & m1_h_p_endress_minilog & $\begin{array}{l}\text { Endress+Hauser Waterpilot } \\
\text { FMX21 }\end{array}$ & Hydrostatic pressure & Minilog RDL10 & $\mathrm{h}$ & $\mathrm{mm}$ & $1 \mathrm{~min}$ & & 03.10 .16 \\
\hline m1 (manhole in lake) & m1_h_p_endress_coolpix & $\begin{array}{l}\text { Endress+Hauser Waterpilot } \\
\text { FMX21 }\end{array}$ & Hydrostatic pressure & $\begin{array}{l}\text { COOLPIX } \\
\text { AW100 }\end{array}$ & $\mathrm{h}$ & $\mathrm{mm}$ & $<1 \mathrm{sec}$ & & 05.10 .16 \\
\hline m1 (manhole in lake) & ml_h_p_endress_logi & $\begin{array}{l}\text { Endress+Hauser Waterpilot } \\
\text { FMX21 }\end{array}$ & Hydrostatic pressure & Logitec c920 & $\mathrm{h}$ & $\mathrm{mm}$ & $1 \mathrm{sec}$ & & 05.10 .16 \\
\hline $\begin{array}{l}\text { p2 (leading to overflow } \\
\text { manhole) }\end{array}$ & p2_q_us_nivus & Nivus CSM-V1D0 & Ultrasonic doppler & Nivus PCM Pro & Q & $\mathrm{L} / \mathrm{s}$ & $5 \mathrm{sec}$ & & 03.10 .16 \\
\hline $\begin{array}{l}\text { p2 (leading to overflow } \\
\text { manhole) }\end{array}$ & p2_h_p_nivus & Nivus CSM-V1D0 & Hydrostatic pressure & Nivus PCM Pro & $\mathrm{h}$ & $\mathrm{mm}$ & $5 \mathrm{sec}$ & & 03.10 .16 \\
\hline r3 (manhole opening) & r3_t_onset_1 & Onset TMC6-HD & Temperature & $\begin{array}{ll}\text { Onset } & \text { HOBO } \\
\text { U12-006 } & \\
\end{array}$ & $\mathrm{T}$ & $\mathrm{C}$ & $1 \mathrm{sec}$ & & 03.10 .16 \\
\hline
\end{tabular}




\begin{tabular}{|c|c|c|c|c|c|c|c|c|}
\hline r3 (manhole opening) & r3_t_onset_2 & Onset TMC6-HD & Temperature & $\begin{array}{ll}\text { Onset } & \text { HOBO } \\
\text { U12-006 } & \end{array}$ & $\mathrm{T}$ & $\mathrm{C}$ & $1 \mathrm{sec}$ & 03.10 .16 \\
\hline r3 (manhole opening) & r3_t_onset_3 & Onset TMC6-HD & Temperature & $\begin{array}{l}\text { Onset } \\
\text { U12-006 }\end{array}$ & $\mathrm{T}$ & $\mathrm{C}$ & $1 \mathrm{sec}$ & 03.10 .16 \\
\hline r3 (manhole opening) & r3_t_onset_4 & Onset TMC6-HD & Temperature & $\begin{array}{ll}\text { Onset } & \text { HOBO } \\
\text { U12-006 } & \end{array}$ & $\mathrm{T}$ & $\mathrm{C}$ & $1 \mathrm{sec}$ & 03.10 .16 \\
\hline m2 (overflow manhole) & m2_h_p_endress_minilog & $\begin{array}{l}\text { Endress+Hauser Waterpilot } \\
\text { FMX } 21\end{array}$ & Hydrostatic pressure & Minilog RDL10 & $\mathrm{h}$ & $\mathrm{mm}$ & $1 \mathrm{~min}$ & 03.10 .16 \\
\hline m2 (overflow manhole) & m2_h_p_endress_coolpix & $\begin{array}{l}\text { Endress+Hauser Waterpilot } \\
\text { FMX21 }\end{array}$ & Hydrostatic pressure & $\begin{array}{l}\text { COOLPIX } \\
\text { AW100 }\end{array}$ & $\mathrm{h}$ & $\mathrm{mm}$ & $<1 \mathrm{sec}$ & 05.10 .16 \\
\hline m2 (overflow manhole) & m2_h_p_endress_logi & $\begin{array}{l}\text { Endress+Hauser Waterpilot } \\
\text { FMX } 21\end{array}$ & Hydrostatic pressure & Logitec c920 & $\mathrm{h}$ & $\mathrm{mm}$ & $1 \mathrm{sec}$ & 05.10 .16 \\
\hline c3 (laminar channel) & c3_h_us_nivus & NivuCompact 3 & Ultrasonic & $\begin{array}{l}\text { Nivus OCM Pro } \\
\text { CF }\end{array}$ & $\mathrm{h}$ & $\mathrm{mm}$ & $5 \mathrm{sec}$ & 03.10 .16 \\
\hline c3 (laminar channel) & c3_v_radar_nivus & Nivus OFR & Radar & $\begin{array}{l}\text { Nivus OCM Pro } \\
\text { CF }\end{array}$ & $\mathrm{v}$ & $\mathrm{m} / \mathrm{s}$ & $5 \mathrm{sec}$ & 03.10 .16 \\
\hline c3 (laminar channel) & c3_h_us_hach & Hach Flodar & Radar & Hach logger & $\mathrm{h}$ & $\mathrm{mm}$ & $1 \mathrm{~min}$ & 03.10 .16 \\
\hline c3 (laminar channel) & c3_v_radar_hach & Hach Flodar & Radar & Hach logger & $\mathrm{v}$ & $\mathrm{m} / \mathrm{s}$ & $1 \mathrm{~min}$ & 03.10 .16 \\
\hline s5 (exit shaft) & s5_h_us_maxbotix_1 & Maxbotix MB7369 & Ultrasonic & Labview script & $\mathrm{d}$ & $\mathrm{mm}$ & $6 / \mathrm{sec}$ & 03.10 .16 \\
\hline s5 (exit shaft) & s5_h_us_maxbotix_2 & Maxbotix MB7369 & Ultrasonic & Labview script & $\mathrm{d}$ & $\mathrm{mm}$ & $6 / \mathrm{sec}$ & 06.10 .16 \\
\hline p6 (exit flow stabilizer) & p6_q_us_nivus & Nivus CSM-V1D0 & Ultrasonic doppler & Nivus PCM Pro & Q & $1 / \mathrm{s}$ & $5 \mathrm{sec}$ & 03.10 .16 \\
\hline p6 (exit flow stabilizer) & p6_h_p_nivus & Nivus CSM-V1D0 & Hydrostatic pressure & Nivus PCM Pro & $\mathrm{h}$ & $\mathrm{m}$ & $5 \mathrm{sec}$ & 03.10 .16 \\
\hline $\begin{array}{l}\text { m3 (manhole in } \\
\text { basement) }\end{array}$ & m3_h_p_endress_minilog & $\begin{array}{l}\text { Endress+Hauser Waterpilot } \\
\text { FMX21 }\end{array}$ & Hydrostatic pressure & Minilog RDL10 & $\mathrm{h}$ & $\mathrm{mm}$ & $1 \mathrm{~min}$ & 03.10 .16 \\
\hline $\begin{array}{l}\mathrm{m3} \text { (manhole in } \\
\text { basement) }\end{array}$ & m3_h_p_endress_coolpix & $\begin{array}{l}\text { Endress+Hauser Waterpilot } \\
\text { FMX21 }\end{array}$ & Hydrostatic pressure & $\begin{array}{l}\text { COOLPIX } \\
\text { AW100 }\end{array}$ & $\mathrm{h}$ & $\mathrm{mm}$ & $<1 \mathrm{sec}$ & 05.10 .16 \\
\hline $\begin{array}{l}\operatorname{m3} \text { (manhole in } \\
\text { basement) }\end{array}$ & m3_h_p_endress_logi & $\begin{array}{l}\text { Endress+Hauser Waterpilot } \\
\text { FMX21 }\end{array}$ & Hydrostatic pressure & Logitec c920 & $\mathrm{h}$ & $\mathrm{mm}$ & $1 \mathrm{sec}$ & 05.10 .16 \\
\hline $\begin{array}{l}\mathrm{m} 3 \text { (manhole in } \\
\text { basement) }\end{array}$ & m3_h_p_hach & Hach AV9000 & Hydrostatic pressure & Hach logger & $\mathrm{h}$ & $\mathrm{mm}$ & $1 \mathrm{~min}$ & 05.10 .16 \\
\hline s6 (basement) & s6_h_us_maxbotix & Maxbotix MB7369 & Ultrasonic & Labview script & $\mathrm{d}$ & $\mathrm{mm}$ & $6 / \mathrm{sec}$ & 03.10 .16 \\
\hline s3 (artificial lake) & s3_cam1_instar & Instar & Video & $\begin{array}{l}\text { Desktop } \\
\text { computer }\end{array}$ & - & - & $26 / \mathrm{sec}$ & 03.10 .16 \\
\hline $\begin{array}{l}\text { r3 (overflow manhole } \\
\text { opening) }\end{array}$ & r3_cam2_instar & Instar & Video & $\begin{array}{l}\text { Desktop } \\
\text { computer }\end{array}$ & - & - & $26 / \mathrm{sec}$ & 03.10 .16 \\
\hline c3 (laminar channel) & c3_cam3_instar & Instar & Video & $\begin{array}{l}\text { Desktop } \\
\text { computer }\end{array}$ & - & - & $26 / \mathrm{sec}$ & 03.10 .16 \\
\hline c4 (2d overland flow) & c4_cam4_instar & Instar & Video & $\begin{array}{l}\text { Desktop } \\
\text { computer }\end{array}$ & - & - & $26 / \mathrm{sec}$ & 03.10 .16 \\
\hline s6 (basement) & s6_cam5_instar & Instar & Video & $\begin{array}{l}\text { Desktop } \\
\text { computer }\end{array}$ & - & - & $26 / \mathrm{sec}$ & 03.10 .16 \\
\hline
\end{tabular}

